OPEN ACCESS

Edited by:

Carlo Alberto Artusi,

University of Turin, Italy

Reviewed by:

Ron Alterman

Beth Israel Deaconess Medical Center and Harvard Medical School, United States

Mauro Porta,

Scientific Institutes of Hospitalization and Care, Italy

*Correspondence:

Laura Wehmeye

laura.wehmeyer@uk-koeln.de

Specialty section: This article was submitted to

Experimental Therapeutics, a section of the journal

Frontiers in Neurology

Received: 01 September 2021 Accepted: 21 September 2021 Published: 20 October 2021

Citation:

Wehmeyer L, Schüller T, Kiess J,

Heiden $P$, Visser-Vandewalle $V$, Baldermann JC and Andrade P (2021) Target-Specific Effects of Deep Brain Stimulation for Tourette Syndrome: A Systematic Review and Meta-Analysis.

Front. Neurol. 12:769275. doi: 10.3389/fneur.2021.769275

\section{Target-Specific Effects of Deep Brain Stimulation for Tourette Syndrome: A Systematic Review and Meta-Analysis}

\author{
Laura Wehmeyer ${ }^{1 *}$, Thomas Schüller ${ }^{2}$, Jana Kiess ${ }^{2}$, Petra Heiden ${ }^{1}$, \\ Veerle Visser-Vandewalle ${ }^{1}$, Juan Carlos Baldermann ${ }^{2,3}$ and Pablo Andrade ${ }^{1}$
}

${ }^{1}$ Faculty of Medicine and University Hospital Cologne, Department of Stereotactic and Functional Neurosurgery, University of Cologne, Cologne, Germany, ${ }^{2}$ Faculty of Medicine and University Hospital Cologne, Department of Psychiatry and Psychotherapy, University of Cologne, Cologne, Germany, ${ }^{3}$ Faculty of Medicine and University Hospital Cologne, Department of Neurology, University of Cologne, Cologne, Germany

Background: Extended research has pointed to the efficacy of deep brain stimulation (DBS) in treatment of patients with treatment-refractory Tourette syndrome (TS). The four most commonly used DBS targets for TS include the centromedian nucleus-nucleus ventrooralis internus (CM-Voi) and the centromedian nucleus-parafascicular (CM-Pf) complexes of the thalamus, and the posteroventrolateral (pvIGPi) and the anteromedial portion of the globus pallidus internus (amGPi). Differences and commonalities between those targets need to be compared systematically.

Objective: Therefore, we evaluated whether DBS is effective in reducing TS symptoms and target-specific differences.

Methods: A PubMed literature search was conducted according to the PRISMA guidelines. Eligible literature was used to conduct a systematic review and meta-analysis.

Results: In total, 65 studies with 376 patients were included. Overall, Yale Global Tic Severity Scale (YGTSS) scores were reduced by more than 50 in $69 \%$ of the patients. DBS also resulted in significant reductions of secondary outcome measures, including the total YGTSS, modified Rush Video-Based Tic Rating Scale (mRVRS), Yale-Brown Obsessive Compulsive Scale (YBOCS), and Becks Depression Inventory (BDI). All targets resulted in significant reductions of YGTSS scores and, with the exception of the CM-Pf, also in reduced YBOCS scores. Interestingly, DBS of pallidal targets showed increased YGTSS and YBOCS reductions compared to thalamic targets. Also, the meta-analysis including six randomized controlled and double-blinded trials demonstrated clinical efficacy of DBS for TS, that remained significant for GPi but not thalamic stimulation in two separate meta-analyses.

Conclusion: We conclude that DBS is a clinically effective treatment option for patients with treatment-refractory TS, with all targets showing comparable improvement rates. Future research might focus on personalized and symptom-specific target selection.

Keywords: Tourette syndrome, tic disorders, deep brain stimulation, DBS, neuromodulation, systematic review, meta-analysis 


\section{INTRODUCTION}

Tourette syndrome (TS) is a neurodevelopmental disorder characterized by motor and vocal tics. Tics have an onset in childhood and reach their peak between 10 and 12 years of age (1). A majority of patients experience reduced symptoms by late adolescence or early adulthood. Nevertheless, around $20 \%$ of patients continue to experience persistent, distressing, and even painful tics throughout adulthood (2). Tics can have a great influence on the patient's overall health and well-being, as they may disrupt daily functioning and adversely affect the quality of life $(3,4)$. The pathophysiology of TS is related to disturbances of a complex neural network with dysregulations of the cortico-basal ganglia-thalamo-cortical (CBGTC) circuits being of predominant importance (5-9). The sensorimotor circuit, but also the limbic and associative circuits are implicated in the heterogenous pathophysiology of TS $(5,10-12)$. Therefore, TS is in many cases accompanied by comorbidities such as attentiondeficit hyperactivity disorder (ADHD), obsessive-compulsive disorder (OCD), or depression $(13,14)$. Importantly, comorbid disorders are associated with increased social problems and reduced quality of life (15). Conventional treatment approaches for TS include pharmacological and behavioral therapy that are beneficial for a majority of patients (16-19). Nonetheless, some patients do not respond to these treatments and remain severely affected. An alternative and safe treatment option for those treatment-refractory patients constitutes deep brain stimulation (DBS) (20).

In 1999, DBS for TS was introduced by Vandewalle et al. (21). The original target chosen by this group was the centromedian nucleus-substantia periventricularis-nucleus ventro-oralis internus complex (CM-Spv-Voi), informed by the experiences of Hassler and Dieckmann (22) with stereotactic thalamic lesions in this region. Thereafter, different targets have been selected based on the involvement of the CBGTC-circuits in TS pathophysiology. The most commonly used targets for TS include different thalamic nuclei and the globus pallidus internus (GPi). Within the thalamus, the centromedian nucleusnucleus ventrooralis internus (CM-Voi) and the centromedian nucleus-parafascicular (CM-Pf) complexes have been used most frequently. This was motivated by their diverse connections to subcortical and cortical regions, including motor, associative, and limbic areas (23-25). The GPi consists of an anteromedial part $(\mathrm{amGPi})$, which is densely connected with associative and limbic networks, and a posteroventrolateral part (pvlGPi), which mainly projects to sensorimotor areas $(26,27)$. Based on this differentiation, it can be assumed that the pvlGPi may be particularly effective in reducing tic symptoms, while the amGPi might be especially effective for the treatment of comorbid OCD symptoms (28-32). The selection of an ideal target for TS treatment is still a matter of debate and differences regarding clinical relevance remain unclear (33-38). Beyond that, target selection is complicated by the fact that the mechanism of action of DBS is still not fully understood, although, there is a growing consensus among researchers that DBS may exert its therapeutic effects by modulating the activity of widespread networks $(20,39-41)$. To date, the target choice is often a matter of preference of the centers, based on their surgical experience (42). On the contrary, some researchers have emphasized the idea that target selection should ideally be based on the individual characteristics of each patient. Hence, the patient's individual symptomatology and possible comorbid disorders should be taken into account in order to decide on the most appropriate target $(34,43)$.

Our objective was to examine the clinical effects of DBS for TS treatment with a systematic review and meta-analyses. First, we aimed to evaluate whether DBS is capable of reducing TS symptoms in the long-term. Our second goal was to evaluate whether the most commonly used targets, namely the CM-Voi, CM-Pf, the amGPi, and the pvlGPi, lead to different clinical outcomes regarding tic reduction and comorbid OCD symptoms.

\section{METHODS}

\section{Systematic Literature Search}

A systematic literature search was conducted following the guidelines of Preferred Items for Reporting Systematic Reviews and Meta-analyses (PRISMA) (44). A search of the electronic database of PubMed was performed to identify the existing literature investigating the effects of DBS in TS patients. The search terms included "Tourette syndrome OR Gilles de la Tourette syndrome OR Tourette's disorder OR Tic disorder" AND "Deep Brain Stimulation OR DBS." Literature search was narrowed to all available articles published from January 1st 1999 to July 8th 2021. Additionally, two recently published metaanalyses of Baldermann et al. (36) and Xu et al. (38) were screened for additional research articles. In order to be included, studies were required to meet the following conditions: (1) case report, case series, clinical trial, or randomized controlled study of DBS for patients diagnosed with TS or a tic disorder; (2) original, published and peer-reviewed; (3) written in English. Studies were excluded if (1) clinical data of the patients could not be identified, (2) the clinical outcome was not assessed by the Yale Global Tic Severity Scale (YGTSS), or (3) patients had already been described in other articles. Titles and abstracts in each study from the search results were independently screened for eligibility by two researchers (LW and JK).

\section{Data Extraction}

The full text of the screened articles was further checked for eligibility and compliance with selection criteria by two researchers (LW and JK). If necessary, exclusion of duplicates was ensured by screening the patient demographics in the studies. Then, the following data were extracted from all studies included in the quantitative synthesis: first author name and publication year, number of participants, sex, age at surgery, DBS targets, follow-up (FU) range, pre- and post-surgery scores of the global YGTSS, total YGTSS, modified Rush Video-Based Tic Rating Scale (mRVRS), Yale-Brown Obsessive Compulsive Scale (YBOCS), and Becks Depression Inventory (BDI). When possible, individual patient data was gathered from the constituent studies. If two targets were evaluated in one patient, an additional case was added. 


\section{Study Quality Assessment}

The quality of each study was assessed using the classifications scheme developed by French and Gronseth (45). This scheme includes 4 levels of evidence, with level 1 representing highquality studies with low risk of bias and level 4 representing studies with a very high risk of bias. Additionally, the quality of randomized trials was assessed using the Cochrane risk of bias tool for randomized controlled trials (46). Two researchers independently evaluated the risk of bias of each study (LW and $\mathrm{JK})$.

\section{Statistical Analysis}

The global YGTSS score (tic severity + impairment; range: 0100 , highest score representing worst clinical condition) served as primary outcome measure. Secondary tic-related outcome measures included the YGTSS total tic score (tic severity; range: $0-50$ ), as well as the mRVRS. Additional secondary outcome measures included YBOCS and BDI assessments. Cases were weighted by the number of participants included in each individual study. Pre- and post-surgery primary outcome scores were compared using Wilcoxon signed-rank tests. Global YGTSS scores for maximum follow-up as well as for different postoperative time points (T1: $\leq 6$ months; T2: $\leq 12$ months; $\mathrm{T} 3$ : $>12$ months) were compared with baseline scores (T0) across the whole sample. To examine whether YGTSS scores differed for the various postoperative time points Friedman's test was applied. In case of a significant result, post-hoc Dunn tests were conducted and Bonferroni-corrected for multiple comparisons. Regarding the secondary outcome measures, last reported YGTSS total tic, mRVRS, YBOCS and BDI scores were compared with preoperative baseline scores using Wilcoxon signed-rank tests. Subgroup analyses of YGTSS percentage change scores at T2 (6-12 months) were performed using Kruskal-Wallis tests in order to compare the four targets (CM-Pf, CM-Voi, amGPi, and pvlGPi). T2 was chosen as time point for the subgroup analysis because of its clinical relevance and temporal precision compared to T3 and maximum follow-up. Post-hoc pairwise comparisons using the Dunn-Bonferroni approach were performed in the case of significant results. Furthermore, absolute change scores of the YBOCS at maximum follow-up were compared between the four targets using Kruskal-Wallis tests. For the YBOCS scores, maximum follow-up was chosen as time point for the subgroup analysis, because a temporal categorization was not possible due to insufficient data. Again, post-hoc Dunn tests were performed in case of significant results and Bonferroni-corrected for multiple comparisons. Of note, articles were excluded from subgroup analyses if the target was not appropriately specified, or multiple targets were used and outcomes combined. Beyond that, three separate meta-analyses of randomized controlled and double-blinded trials (RCTs) were conducted with the YGTSS total tic score as primary outcome measure. A first metaanalysis was performed to examine the general effect of DBS across all targets. In addition, two separate meta-analyses were conducted including RCTs targeting the thalamus and GPi, respectively. Standardized means of the YGTSS total tic score were compared between the experimental condition (DBS ON) vs. control condition (DBS OFF). A random-effect model was used to account for heterogeneity among studies. Analyses were performed with SPSS 27 and the Review Manager 5.4.1. (47, 48). Significance levels were set at $p<0.05$.

\section{RESULTS}

\section{Study Selection}

The PubMed search of the existing literature on the clinical outcome of DBS in TS patients identified 479 articles. In addition, the meta-analyses by Baldermann et al. (36) and $\mathrm{Xu}$ et al. (38) yielded 57 and 29 studies, respectively. After removing duplicates $(n=75)$, abstracts were screened for the above mentioned selection inclusion criteria, which resulted in the exclusion of 397 records. Full texts of the remaining 93 articles were subsequently checked for eligibility. Among these, 18 articles were excluded because the clinical outcome was not assessed using the YGTSS or YGTSS change was not sufficiently reported (e.g., only improvement rates without baseline values). Thereafter, additional 10 studies were excluded after a thorough analysis, because the study participants had already been reported in other articles. In total, 65 studies were included, of which 58 studies were case reports or case series with an evidence level of four (45). Seven reports were randomized, double-blinded controlled trials, with an evidence level of three. The majority of RCTs had an overall low risk of bias, except for two RCTs, which had some concerns (see details in Supplementary Figure 1). One RCT needed to be excluded because YGTSS scores were only reported for the stimulation $\mathrm{ON}$ setting, but not for the stimulation OFF setting. Another RCT was already excluded during the full text screening, because only percentage changes were reported without raw baseline and follow-up scores. An adapted PRISMA flow diagram is displayed in Figure $\mathbf{1 .}$

\section{Individual Participant Data}

In total, 65 studies with 376 patients were included in the final analysis (see Table 1 for a detailed overview of the included studies). Most of the included patients were male (75.63\%) and the median age was 30.5 years (range: $15-50$ years). Of those 376 patients, $96(25.53 \%)$ were stimulated in the CMVoi, 59 (15.69\%) in the CM-Pf, 100 (26.6\%) in the amGPi, and $81(21.54 \%)$ in the pvlGPi. The four targets are visualized in Figure 2. The ventral anterior/ventrolateral thalamus (VA/VL) was targeted in 11 patients $(2.93 \%)$. In four patients, the thalamus was indicated as target, but not further specified. Similarly, in one case, the GPi without further specification was reported as the target. In two cases, both amGPi and pvlGPi were stimulated. The anterior limb of internal capsule/nucleus accumbens (ALIC/NAc) was targeted in eight patients $(2.13 \%)$. In two other cases electrodes were implanted in the globus pallidus externus (GPe). A total of 12 patients received electrodes in two target areas. In two patients the thalamus and pvlGPi were targeted; however, the thalamus was not further specified. The CM-Voi and ALIC/NAc were targeted in three patients, while the $\mathrm{CM}$ and ALIC/NAc were targeted in one patient. Electrodes in both the amGPi and ALIC/NAc were implanted in two patients and three patients received electrodes in both the pvlGPi and the subthalamic nucleus (STN). In one patient, electrodes were 


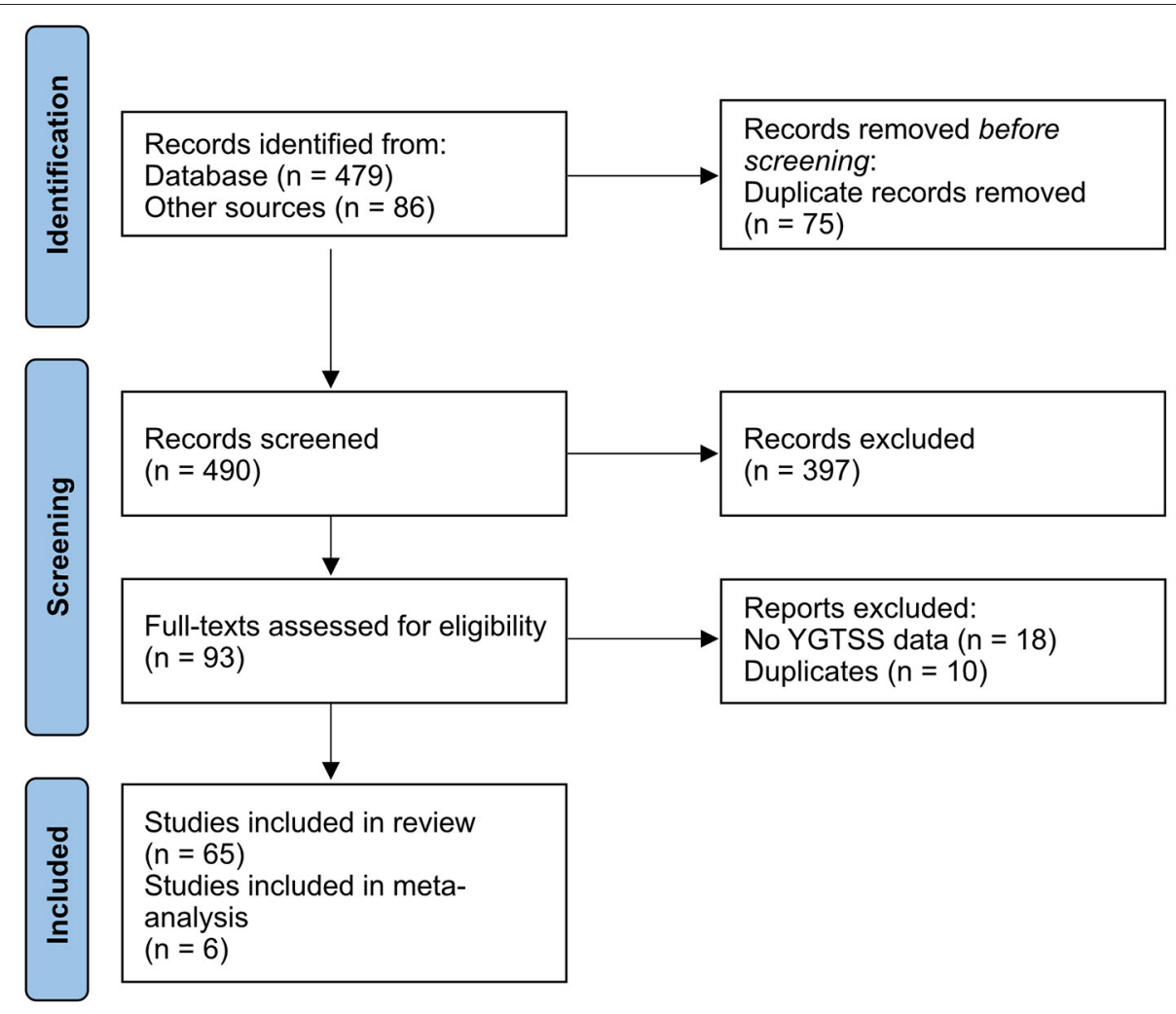

FIGURE 1 | Adapted PRISMA 2020 flow diagram (44).

implanted in the region of the ALIC and the bed of the nucleus of stria terminalis. In another two patients the fields of forel (subthalamus) were targeted. Although most patients received bilateral DBS, six patients underwent unilateral DBS in the pvlGPi and one patient in the amGPi.

\section{Clinical Outcomes Analysis}

Global YGTSS scores for all targets combined were significantly reduced at maximum follow-up $(n=343, Z=-15.97, p$ $<0.001$ ). The follow-up period ranged from 3 to 91 months ( $M d n=25$ months). The median YGTSS score decreased from 79.92 points $(I Q R=13.25)$ to a post-surgery median of 34.69 points $(I Q R=20.93)$, which represents a median reduction rate of $56.59 \%$. Also, $69.4 \%(n=238)$ of the patients experienced a symptom reduction of more than $50 \%$ at maximum followup. Moreover, global YGTSS scores at different postoperative time points (T1: $\leq 6$ months; T2: $\leq 12$ months; T3: $>12$ months) differed significantly from postoperative baseline scores (T0). DBS resulted in a YGTSS median reduction of 34 points at T1 $(n=201, Z=-12.27, p<0.001)$. At T2, global YGTSS scores were reduced by a median of 37 ( $n=190, Z=-11.87$, $p<0.001$ ), whereas median scores decreased by 53.93 at T3 ( $n=123, Z=-9.65, p<0.001)$. Interestingly, clinical efficacy increased significantly over time after surgery. A Friedman's test showed a significant difference between global YGTSS scores at T0, T1, T2, and T3 [ $\left.n=73, \chi^{2}{ }_{(3)}=207.14, p<0.001\right]$. Dunn's post-hoc tests revealed that median YGTSS scores decreased from T0 to T1, from T1 to T2, and from T2 to T3 (T0: $M d n=67.56$, $I Q R=10.44 ; \mathrm{T} 1: M d n=39.12, I Q R=6.18 ; \mathrm{T} 2: M d n=37.00$, $I Q R=2.25$; T3: $M d n=24.07, I Q R=0$ ), which was statistically significant in all cases after Bonferroni adjustments $(p<0.001)$. YGTSS outcomes for the different time points are depicted in Figure 3.

Analysis of secondary tic-related outcome measures revealed that the median of YGTSS total tic scores decreased from 39.12 points $(I Q R=10)$ to 19.0 points $(I Q R=13)$ at maximum follow-up (range: 3-107 months, $M d n=12$ months), which equals a median symptom reduction rate of $50.43 \%(n=159$, $Z=-10.90, p<0.001)$. Results for the MRVRS showed a median reduction of $35.54 \%$ at maximum follow-up (Pre: $M d n=14.00, I Q R=4.06$; Post: $M d n=9.00, I Q R=7.70, n=64$, $Z=-6.57, p<0.001)$. The follow-up period for the MRVRS ranged from 3 to 84 months ( $M d n=12$ months). Regarding comorbid symptoms, the median of YBOCS scores decreased from 20 points $(I Q R=10.82)$ to 11.45 points $(I Q R=7.51)$ at maximum follow-up (range: 3-107 months, $M d n=34$ months), representing a median reduction rate of $43.23 \%(n=206$, $Z=-11.84, p<0.001)$. Of these patients, $68.4 \%(n=141)$ experienced at least a $35 \%$ reduction of OCD, which is the criterion to be considered a responder (122). Finally, the BDI median score declined by a reduction of $50 \%$ from 25.70 points $(I Q R=13.40)$ to 13.85 points $(I Q R=11.30)$ at maximum 
TABLE 1 | Overview of included studies $(n=65)$.

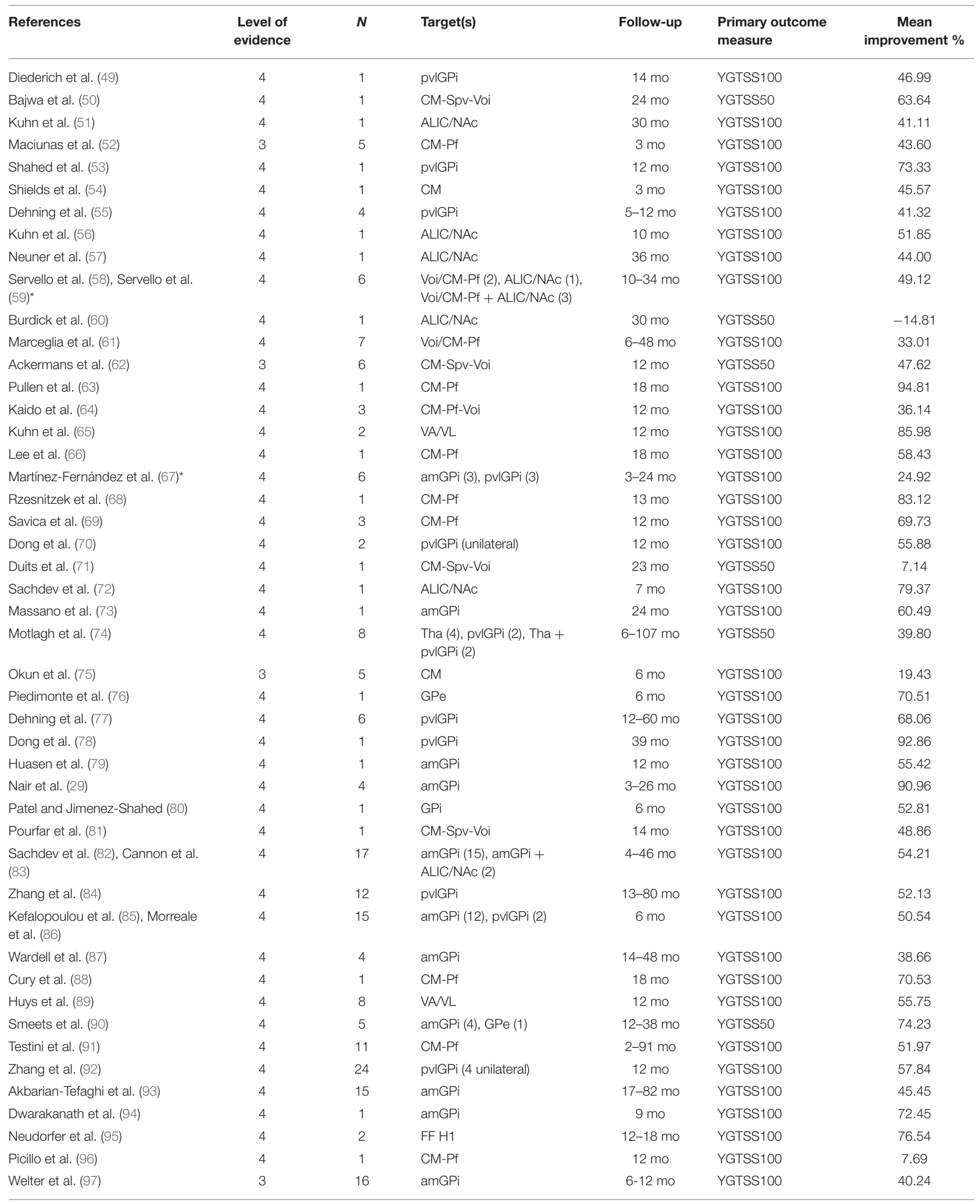


TABLE 1 | Continued

\begin{tabular}{|c|c|c|c|c|c|c|}
\hline References & $\begin{array}{l}\text { Level of } \\
\text { evidence }\end{array}$ & $N$ & Target(s) & Follow-up & $\begin{array}{l}\text { Primary outcome } \\
\text { measure }\end{array}$ & $\begin{array}{c}\text { Mean } \\
\text { improvement \% }\end{array}$ \\
\hline Azimi et al. (98) & 4 & 6 & amGPi & $12 \mathrm{mo}$ & YGTSS100 & 62.56 \\
\hline Doshi et al. (99) & 4 & 2 & amGPi & $18 \mathrm{mo}$ & YGTSS100 & 64.56 \\
\hline Dowd et al. (100) & 4 & 12 & CM-Pf-Voi & $6-58 \mathrm{mo}$ & YGTSS100 & 50.59 \\
\hline Kano et al. (101) & 4 & 2 & CM-Pf-Voi & 29-35 mo & YGTSS100 & 34.13 \\
\hline Richieri et al. (102) & 4 & 1 & VANL & $48 \mathrm{mo}$ & YGTSS50 & 74.36 \\
\hline Brito et al. (103) & 4 & 5 & CM-Pf & $12 \mathrm{mo}$ & YGTSS100 & 30.00 \\
\hline Kakusa et al. (104) & 4 & 1 & $\mathrm{CM}+\mathrm{ALIC} / \mathrm{NAC}$ & $12 \mathrm{mo}$ & YGTSS100 & 84.29 \\
\hline Rossi et al. (105) & 4 & 1 & amGPi (unilateral) & $26 \mathrm{mo}$ & YGTSS100 & 87.10 \\
\hline Zhang et al. (106) & 4 & 1 & pvlGPi & $3 \mathrm{mo}$ & YGTSS100 & 53.19 \\
\hline Zhang et al. (107) & 4 & 10 & pvlGPi & 24-96 mo & YGTSS100 & 81.43 \\
\hline Zhu et al. (108) & 4 & 3 & $\mathrm{pvlGPi}+\mathrm{STN}$ & $6 \mathrm{mo}$ & YGTSS100 & 36.60 \\
\hline Duarte Batista et al. (109) & 4 & 1 & ALIC/BST & $12 \mathrm{mo}$ & YGTSS100 & 81.00 \\
\hline $\begin{array}{l}\text { Servello et al. (30, 58, 110, 111), } \\
\text { Porta et al. (112, 113), Marceglia } \\
\text { et al. (114) }\end{array}$ & 4 & 57 & $\begin{array}{l}\text { Voi-CM-Pf (41), amGPi (14), } \\
\text { ALIC/NAc (2) }\end{array}$ & $24-48 \mathrm{mo}$ & YGTSS100 & 38.94 \\
\hline $\begin{array}{l}\text { Andrade et al. (115), Heiden et al. } \\
\text { (32) }\end{array}$ & 4 & 7 & CM-Voi & $6 \mathrm{mo}$ & YGTSS100 & 42.22 \\
\hline Kimura et al. (116) & 4 & 25 & CM-Pf & $36 \mathrm{mo}$ & YGTSS100 & 56.59 \\
\hline Müller-Vahl et al. (117) & 3 & 10 & CM-Voi (4), pvIGPi (6) & $8-108 \mathrm{mo}$ & YGTSS50 & 26.96 \\
\hline Sun et al. (118) & 4 & 6 & pvlGPi & $26-48 \mathrm{mo}$ & YGTSS100 & 59.62 \\
\hline Baldermann et al. (119) & 4 & 8 & CM-Voi & $12 \mathrm{mo}$ & YGTSS100 & 47.73 \\
\hline
\end{tabular}

Duplicate studies are mentioned. An additional case was added when two targets were evaluated in one patient (*).N, Number of participants; mo, months; YGTSS100, global YGTSS

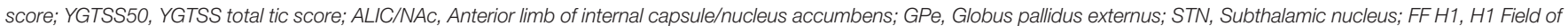
Forel; Tha, Thalamus.
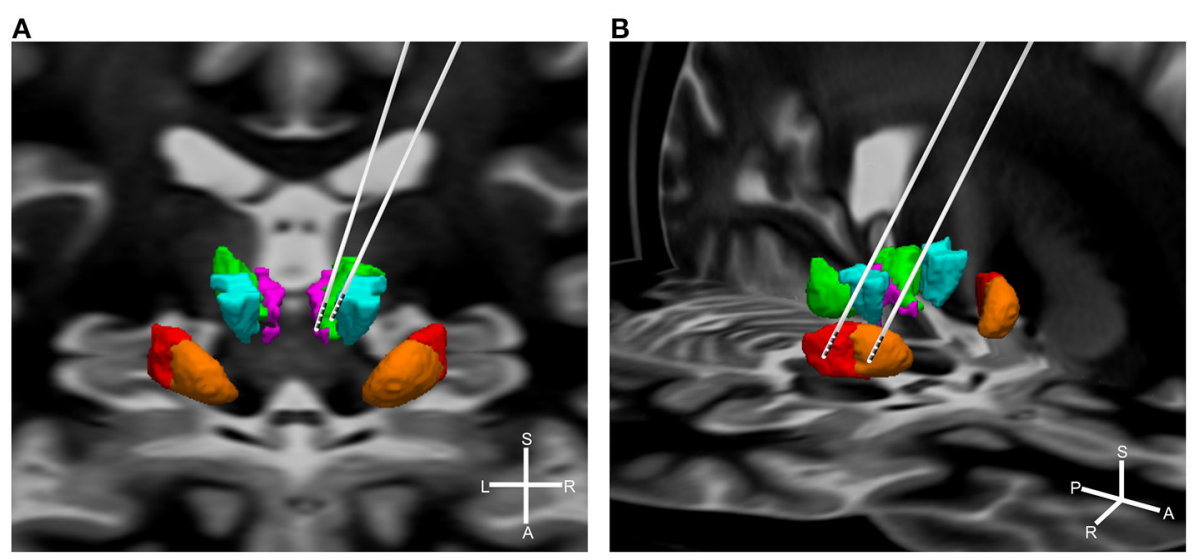

FIGURE 2 | Simplified visualization of DBS electrodes of the different targets. Shown are the target regions: green = CM; purple = Pf; turquoise = Voi; red = pvlGPi; orange $=$ amGPi. For illustration purposes targets are displayed unilateral only. (A) Thalamic targets: left electrode = CM-Pf; right electrode $=$ CM-Voi. Background shows the coronal section of a brain MRI. (B) Pallidal targets: left electrode = pvlGPi; right electrode = amGPi. Background shows the horizontal section of a brain MRI. Graphics were generated using the DISTAL atlas (120) and MNI PD25 atlas (121). S, superior; A, anterior; L, left; R, right.

follow-up, which ranged from 3 to 49.5 months $(M d n=23.5$ months). This reduction was also statistically significant $(n=110$, $Z=-7.71, p<0.001)$.

\section{Subgroup Analysis}

Wilcoxon signed-rank tests revealed that stimulation of all targets resulted in a significant global YGTSS reduction after up to 12 months (see Table 2). Importantly, these target-specific YGTSS percentage changes differed significantly $\left[n=172, \chi^{2}{ }_{(3)}=21.41\right.$, $p<0.001]$. Dunn's pairwise tests showed that the median YGTSS percentage change was significantly larger for pvlGPi compared to CM-Pf $(p<0.001)$ and CM-Voi $(p=0.006)$. Additionally, the median percentage change was significantly larger after amGPi compared to CM-Pf $(p=0.017)$. Other 
pairwise comparisons were not statistically significant. YGTSS outcomes for the different targets are depicted in Figure 4.

Furthermore, Wilcoxon signed-rank tests showed that stimulation of the CM-Voi, amGPi, pvlGPi, but not the CMPf resulted in a significant reduction of YBOCS scores at maximum follow-up (range: $3-84$ months, $M d n=48$ months) (see Table 3). Importantly, only 3 studies were included in the CM-Pf target group $(n=11)$ with a maximum follow-up period of 6 months. Subgroup analysis of the YBOCS absolute change scores showed significant differences across targets, as determined by a Kruskal-Wallis test $\left[n=143, \chi^{2}{ }_{(3)}=26.58\right.$, $p<0.001]$. Bonferroni corrected post-hoc analysis indicated that the median YBOCS absolute change after pvlGPi stimulation was significantly higher than after CM-Voi DBS $(p=0.004)$ and CM-Pf DBS $(p<0.001)$. Additionally, the median absolute change was significantly greater for amGPi DBS compared to CM-Pf DBS $(p=0.011)$. Other pairwise comparisons were not statistically significant. YBOCS outcomes for the different targets are depicted in Figure 5.

\section{Meta-Analyses}

Three separate meta-analyses of randomized controlled and double-blinded trials were conducted with the YGTSS total tic score as primary outcome measure (see Figure 6). The first metaanalysis, which included six studies (FU range $=0.23-6$ months, $M d n=3$ months), showed a significant overall effect of the experimental condition (DBS ON) over the control condition (DBS OFF) for thalamus and GPi targets combined. The test of heterogeneity was not significant, and the overall effect size was -0.66 (CI: $-1.10,-0.22$ ). The second meta-analysis for thalamic DBS included four studies with a total of 27 patients in the experimental group and 25 patients in the control group (FU range $=0.23-6$ months, $M d n=3$ months). The test for the overall effect was not significant at 0.05 level $(p=0.07)$, indicating that YGTSS tic scores did not significantly differ between the experimental and control condition. The overall effect size was -0.72 (CI: $-1.50,0.06)$. In the contrary, results of the third meta-analysis for pallidal DBS (FU $=3$ months) showed a significant overall effect of GPi DBS $(p=0.02)$, favoring stimulation $\mathrm{ON}$ over stimulation OFF. A non-significant heterogeneity and overall effect size of -0.66 (CI: $-1.20,-0.12$ ) were observed.

\section{DISCUSSION}

\section{Summary of Main Findings}

Here, we provide an up-to-date overview of the existing literature to examine the clinical efficacy of DBS in patients with TS. Analysis of global YGTSS scores of 343 individual patients revealed that DBS of all targets combined is capable of reducing TS symptomatology. At maximum follow-up, twothirds of patients experienced a symptom reduction of more
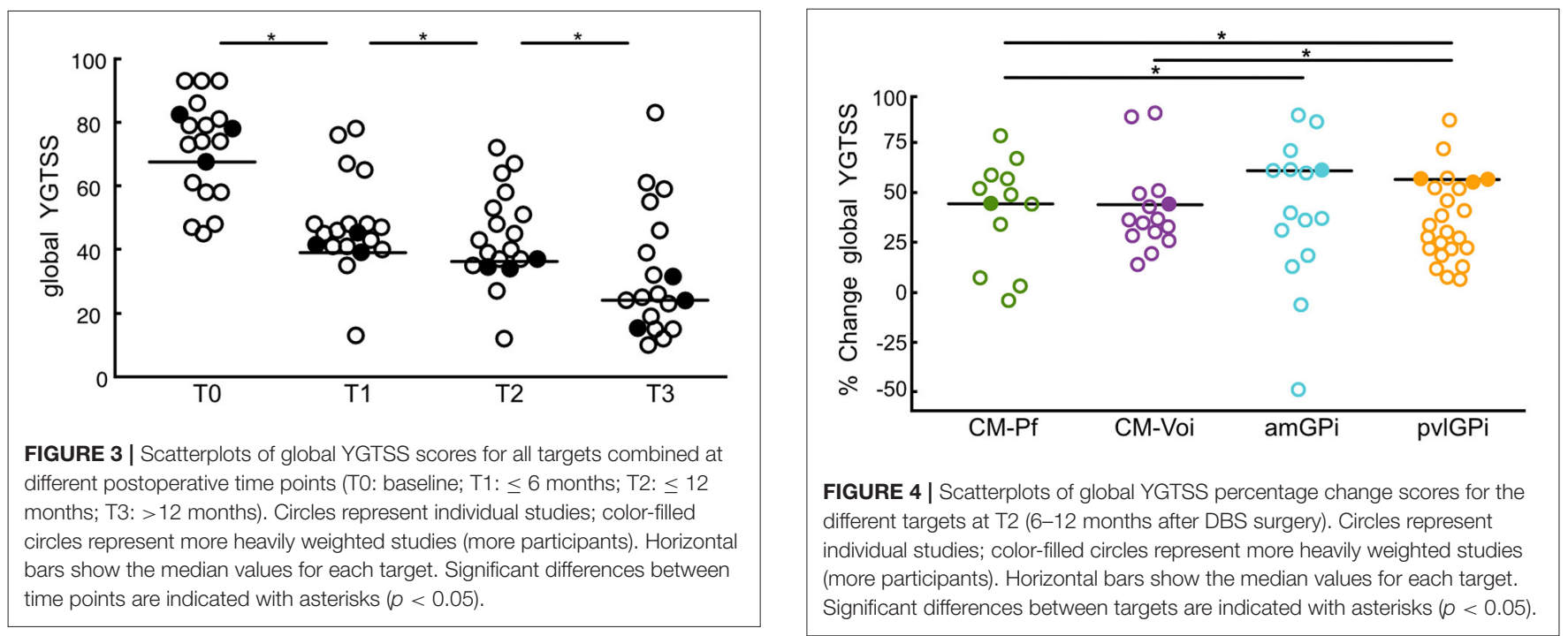

TABLE 2 | Overview of global YGTSS outcomes for the different targets at T2 (6-12 months post-operatively).

\begin{tabular}{|c|c|c|c|c|c|c|}
\hline Target & $N$ & Pre-DBS median & Post-DBS median & Median reduction & Median $\%$ change & $p$-value \\
\hline CM-Pf & 36 & $79.92(0.00)$ & $43.80(0.00)$ & $36.12(0.00)$ & $45.20(0.00)$ & $<0.001$ \\
\hline CM-Voi & 55 & $67.56(0.00)$ & $37.00(0.00)$ & $30.56(0.00)$ & $45.23(0.00)$ & $<0.001$ \\
\hline pvlGPi & 61 & $74.00(8.40)$ & $34.00(3.55)$ & $42.80(15.50)$ & $57.84(13.40)$ & $<0.001$ \\
\hline
\end{tabular}

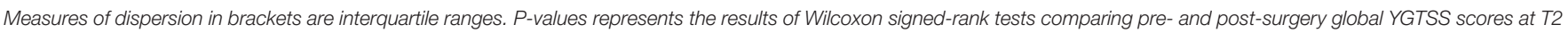
for each target. 
TABLE 3 | Overview of YBOCS outcomes for the different targets after DBS surgery at maximum follow-up.

\begin{tabular}{|c|c|c|c|c|c|c|}
\hline Target & $N$ & Pre-DBS median & Post-DBS median & Median reduction & Median $\%$ change & $p$-value \\
\hline CM-Pf & 11 & $17.60(5.00)$ & $7.00(11.60)$ & $5.60(6.60)$ & $44.44(50.13)$ & 0.102 \\
\hline CM-Voi & 73 & $20.17(3.17)$ & $11.45(0.45)$ & $8.72(2.92)$ & $43.23(0.00)$ & $<0.001$ \\
\hline amGPI & 36 & 19.50 (11.43) & $10.69(4.12)$ & $11.50(15.55)$ & $55.17(46.42)$ & $<0.001$ \\
\hline pvlGPi & 23 & $24.70(7.00)$ & $3.20(9.30)$ & 16.50 (10.50) & 87.04 (30.15) & $<0.001$ \\
\hline
\end{tabular}

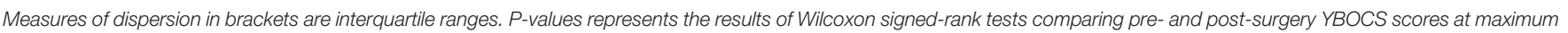
follow-up for each target.

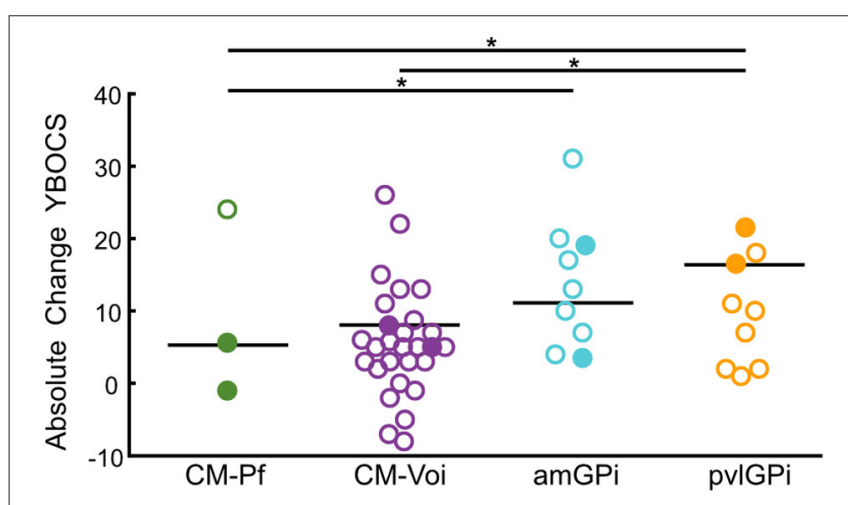

FIGURE 5 | Scatterplots of YBOCS absolute change scores for the different targets at maximum follow-up. Circles represent individual studies; color-filled circles represent more heavily weighted studies (more participants). Horizontal bars show the median values for each target. Significant differences between targets are indicated with asterisks $(p<0.05)$.

than $50 \%$. Considering the time course of symptom improvement after DBS-surgery, our results show that global YGTSS scores were already reduced after 6 months. Importantly, thereafter the clinical benefits of DBS increased even further. Moreover, the present results revealed that DBS resulted in significant reductions of other tic-related outcome measures (MRVRS, YGTSS total tic score) as well as comorbidities (YBOCS, BDI). The meta-analysis of six RCTs including thalamic and pallidal targets further confirmed the clinical efficacy of DBS.

Additionally, we compared the clinical outcomes of the most commonly used DBS targets, namely CM-Pf, CM-Voi, amGPi, and pvlGPi. Stimulation of all targets resulted in a significant reduction of global YGTSS scores between 6 and 12 months. However, stimulation of the GPi led to an even larger reduction rate of tic symptoms compared to thalamic stimulation. Specifically, pvlGPi DBS showed higher reduction rates of global YGTSS scores compared to CM-Pf and CMVoi DBS. Reduction rates were also greater for amGPi DBS compared to CM-Pf DBS. Results of the two separate metaanalyses revealed a significant effect for GPi stimulation, but not for thalamic stimulation. Moreover, stimulation of all targets except for the CM-Pf resulted in a significant reduction of YBOCS scores at maximum follow-up. Also, pvlGPi DBS led to increased OCD symptom reduction compared to CM-Pf and CM-Voi DBS at maximum follow-up. Similarly, stimulation of amGPi led to increased OCD symptom reduction compared to CM-Pf stimulation.

\section{Interpretation of Main Findings}

Based on the present results, we suggest that DBS is capable of reducing TS symptomatology in patients with treatmentrefractory TS, which is in line with previous research $(36,37$, 123). DBS significantly reduces tic-related symptoms as well as comorbid OCD and affective symptoms in TS patients. The latter finding is of great importance, since it is common that patients with TS exhibit at least one comorbid disorder $(3,15,124)$. Moreover, time appears to play an important role in DBS for TS, as the beneficial effects of DBS seem to increase up to more than 1 year after surgery. Recent evidence implicates that this is not the case with conservative therapies, including pharmacological and behavioral therapy, which effects tend to decline over time (123). The individual optimization of stimulus parameters, especially during the first 6 months after surgery, likely contributes to this particular time course of DBS effects (74). Of note, our results are mainly based on the analysis of case reports or case series with an evidence level of four (45). The meta-analysis for all targets combined, which also pointed to the efficacy of DBS in TS, included only six RCTs with several limitations including a high heterogeneity in terms of time frame, procedure, outcome measures and target selection. In order to move away from the experimental use of DBS for TS patients, additional randomized controlled and double-blinded trials are needed. At the same time, RCTs with larger cohorts are almost impossible in TS because the number of candidates for DBS may not be sufficient. Nevertheless, future RCTs should strive to use consistent and comparable study designs.

Importantly, the present results demonstrate that stimulation of all targets lead to a significant tic reduction following DBS surgery. Similarly, stimulation of all targets except for the CMPf result in significant reductions of OCD symptoms. Results of the subgroup analyses also indicate that the clinical outcomes of DBS differ among the four targets. However, these results should be interpreted with great caution due to several reasons. On the one hand, we cannot rule out the possibility that the results of the subgroup analysis are influenced by our categorization of the individual targets. We have tried to categorize the targets as accurately as possible based on the description of the target locations in the original articles. However, especially in the two thalamic target groups, the individual targets within a categorization are likely to vary, because of the size as well as the complex nomenclature of the thalamus (125, 126). Also, even if authors specify the same surgical target, targets can still be slightly different. For example, personal correspondences showed that the CM-Voi target used by Servello et al. (127) is 


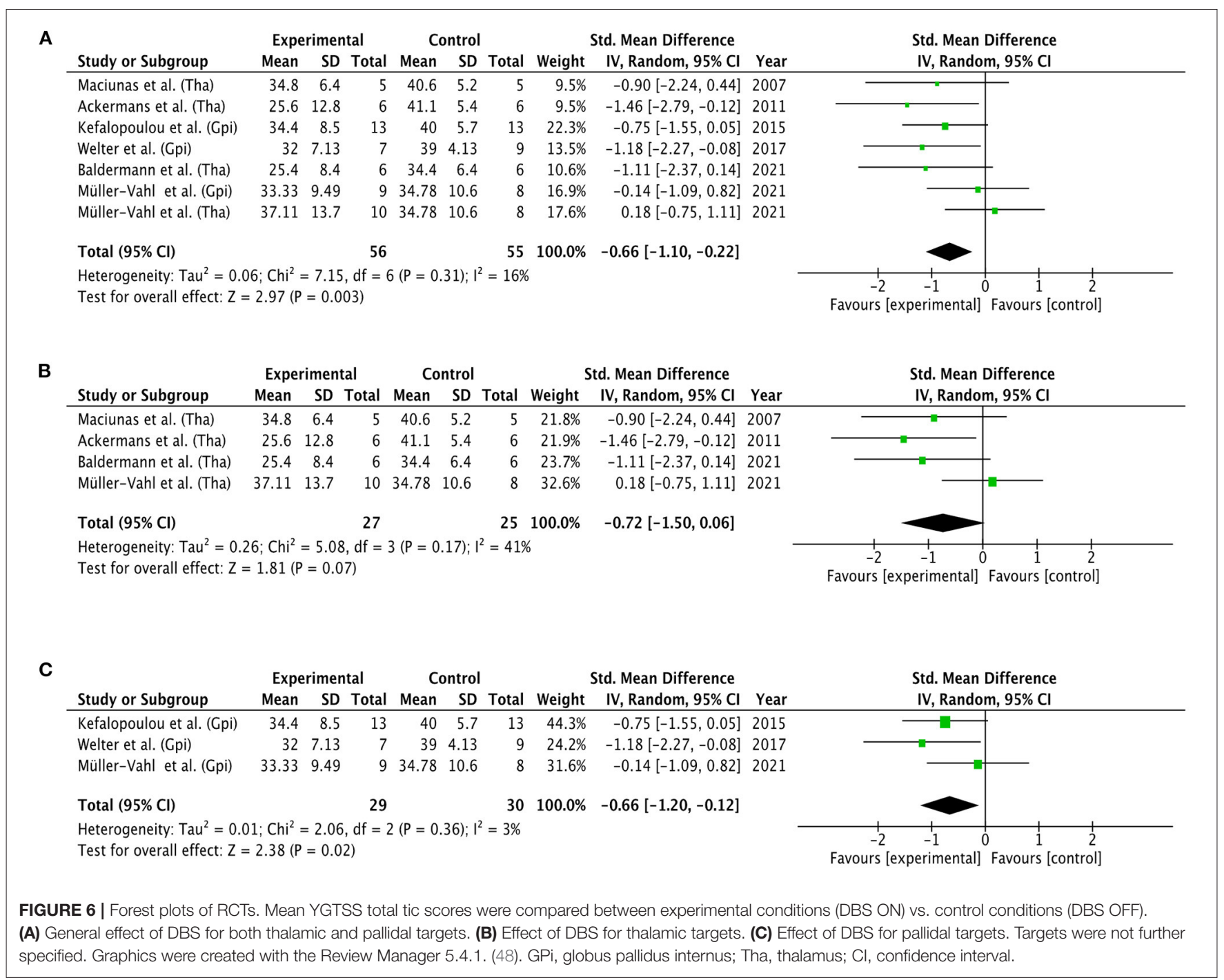

located $2 \mathrm{~mm}$ further anterior to the CM-Voi target of VisserVandewalle et al. $(21,110)$. Additionally, the actual volume of tissue activated (VTA) is highly dependent on factors such as the exact electrode position, stimulation settings, and individual anatomy. Furthermore, it cannot be ruled out that the results are confounded by a systematic bias in patient selection. Because of the relatively small sample sizes in target groups, clinical outcomes may be influenced by the patient selection of a single center, as patient selection processes may differ from site to site. Certain selection criteria, such as age, tic severity and impairment were shown to significantly influence clinical outcomes after DBS (36). Regarding the post-surgery time periods included in our analyses, it should be kept in mind that tic reduction rates after 6 to 12 months were compared between targets; meaning that the present analysis of the YGTSS showed differences between the targets up to 1 year after surgery. On the contrary, for the YBOCS, targets were compared at maximum follow-up, ranging from 3 to 84 months, which is a very broad time period. Similarly, studies included in the meta-analysis for thalamic DBS ranged from 7 days to 6 months, which is still a broad time period. Based on the present findings, one may argue that it is challenging to compare such temporally heterogeneous results.

Nonetheless, results of the subgroup analyses particularly emphasize the high capability of pallidal DBS to reduce tic symptoms up to 1 year following DBS surgery. In line with our findings, pvlGPi has proven to be an effective target for patients with other motor dysfunctions, such as Parkinson's disease and dystonia $(33,128-130)$. Therefore, the pvlGPi is also preferably chosen for DBS in TS patients with dystonic tics $(67,85)$. Given its anatomical connections to sensorimotor regions, the modulation of these fibers seem like a probable mechanism of action for pvlGPi DBS $(28,32)$. However, stimulation of projections from pvlGPi to sensorimotor networks was found to correlate negatively or not at all with tic improvement (31, 131). The amGPi was previously thought to be a particularly effective target for TS patients with comorbid OCD symptoms, but according to the present results, it may also play an equally important role in tic reduction (30). In line with 
this, registry data demonstrated that amGPi DBS resulted in the greatest tic improvement after 1 year compared to CM, pvlGPi and ALIC DBS; however differences between targets were not significant (37). Concurrently, connectivity from the amGPi to limbic and associative networks positively correlated with tic improvement $(31,131)$. Interestingly, activation of the sensorimotor pallido-subthalamic pathway was more predictive of OCD symptom improvement compared to the associative pallido-subthalamic pathway (131). This agrees with our findings, which demonstrated the high capability of pvlGPi and amGPi DBS in reducing OCD symptoms. Surprisingly, the current findings partly differ from what we know from previous reports and are not entirely consistent with the functionally distinction of sensorimotor, associative, and limbic pathways. It should be noted that TS is no pure motor disorder (132). Heterogeneity and complexity of the disorder might partly explain the tic improvement following amGPi DBS and OCD symptom improvement after pvlGPi DBS (131, 133). Additionally, the different targets might improve TS symptomatology through different functional mechanisms, such as direct inhibition of tic execution or enhancement of the ability to suppress tics $(134,135)$. However, the exact causal relationships are not understood, and further research is needed to explain this inverse differentiation of the pallidal DBS targets.

Beyond that, the present results suggest that thalamic DBS yields lower tic reduction rates compared to pallidal DBS up to 12 months postoperatively. To our knowledge, no significant differences have to date been found between targets in terms of tic reduction rates $(36-38,136)$. Only a few studies compared the clinical effects of thalamic stimulation with those of pallidal stimulation, which indeed pointed to a superior effect of the latter, but only up to 3 months $(117,137,138)$. However, as our findings show, it may take at least 1 year for the positive effects of DBS to fully develop. Accordingly, YGTSS reduction was shown to be greater at least 1 year after CM-Pf DBS compared to $<1$ year (91). Moreover, although the initial positive effects of GPi DBS have been shown to decrease several years after surgery, the beneficial effects from CM-Voi DBS were ongoing in a subset of patients $(117,139)$. Based on this, we cannot rule out differences in clinical time courses between targets, but long-term results are rare and further investigations are needed. Apart from that, results of our meta-analysis revealed a non-significant effect of DBS for thalamic targets. It should be noted that this finding was predominantly shaped by a single RCT favoring stimulation OFF over stimulation ON, which was weighted with $32.6 \%$ (for details see Figure 6). According to the authors, results of this trials might be influenced by poor compliance, placebo effect, and high infection rate (117). Also, in three patients, electrode positions did not correspond to the planned target point and extended into subthalamic regions, which in turn may have compromised optimal stimulation settings, eventually resulting in under-stimulation (117). Furthermore, our results revealed that thalamic DBS targets are less capable of alleviating OCD symptoms than pallidal targets. In particular, CM-Pf DBS was found to have no effect at all. This result is rather surprising, because of the connections between the CM-Pf and limbic regions, especially the nucleus accumbens (23-25). However, it should be noted that only 3 studies were included in the CMPf target group $(n=11)$ with a maximum follow-up period of 6 months. As already discussed above, the results are also highly dependent on the patient selection and the type and severity of the OCD symptoms. Centers tend to target the amGPi or ALIC/NAc for patients with more severe OCD symptoms, while CM-Pf is preferably chosen for patients with predominant tic symptoms (140).

Finally, it needs to be mentioned that despite the effectiveness of the various DBS targets, other factors also play a role in the selection of targets. In the present review, no differences in side effects between the targets have been taken into account, because a quantitative evaluation of adverse events was not feasible due to lack of information. Ideally the safety of DBS should also be assessed in the same way. Side effects may vary across the four targets, which could influence the final decision on target selection for DBS of individual patients. Some other technical details are also not considered, such as the substantial amount of total energy needed for GPi stimulation compared to thalamic stimulation, which may result in reduced battery life duration, leading to more frequent battery replacements in the case of non-rechargeable implanted pulse generators (141).

To sum up, it should be emphasized that the present results do not provide an answer to the question of which target is more clinically relevant for the treatment of TS. Rather, they highlight the importance of considering which target might be the best choice for the individual patients based on specific symptoms and individual characteristics. Future studies might focus on defining precise criteria and guidelines for the target selection for DBS in TS.

\section{Future Directions for DBS Targeting in TS}

Connectomic DBS represents a unique opportunity to guide target selection in psychiatric disorders that are heterogenous, such as Tourette Syndrome $(39,142,143)$. The application of DTI tractography has the great potential to shift the focus away from identifying one appropriate target for TS and instead enable for personalized and symptom-specific targeting. Specifically, a connectomic approach may allow to display the fiber pathways associated with specific symptom improvement. Identification of such connectivity patterns could potentially lead to the optimization of targets or discovery of new targets. Several studies have investigated structural connectivity patterns in DBS for TS $(31,32,103,115,131,144)$. Importantly, studies showed that the VTA of the target alone did not predict the clinical efficacy of DBS for TS $(103,145)$. Instead, results of several studies indicated that the connectivity between the VTA and cortical regions was linked to the clinical outcome after DBS in TS patients $(31,32,103,115)$. However, the various targets used for DBS in TS show different connectivity profiles, and cortical networks linked to clinical improvement have been shown to differ across targets $(31,32)$. In particular, networks positively correlated with tic improvement included limbic and associative regions for the GPi, and sensorimotor as well as parietal-temporal-occipital regions for the thalamus. For both targets, connectivity to the cerebellum also correlated positively with tic improvement (31). This suggests that stimulation of 
the different targets does not result in the modulation of a single network. Rather, stimulation of the different targets might result in the modulation of distinct, maybe partly overlapping networks, which then lead to the improvement of specific symptoms via a certain functional mechanism. DBS should aim to target those symptom-specific networks, thereby allowing to treat the entire complex spectrum of TS symptoms. Further studies examining the clinical outcomes of DBS in TS with known targets using structural imaging techniques are needed to improve our understanding of the underlying DBS mechanisms and to increase the efficacy of target selection. Particularly, there is a need for studies that identify fiber pathways associated with improvement of various TS symptoms, including simple tics, complex tics, the premonitory urge, comorbid symptoms, as well as tic suppression. In addition, the functional mechanisms by which modulation of the network ultimately improves tic symptoms (e.g., by directly inhibiting tic execution or by improving the ability to suppress tics) should also be investigated.

\section{Limitations}

There are several limitations of the present review. As already mentioned above, the most obvious limitation is that our results are mainly based on case reports and case series with a high risk of bias. In addition, not all individual data were available, and aggregate data had to be extracted for some studies. This was mitigated by weighting the data by sample size for statistical analysis. Regarding the subgroup analyses, the numbers of patients in each target group varied. Notably, the number of patients in the CM-Pf target group for the YBOCS subgroup analysis was very low. The meta-analysis for all targets combined included only six RCTs, with a high heterogeneity in terms of time frame, procedure, outcome measures and target selection. Considering that the effects of DBS continue to manifest up to more than 12 months after surgery, one could argue that the included RCTs are also generally too short. Next, when drawing conclusions, one should be aware that the included articles in the present systematic review represent a very heterogenous data pool. The significant effects might be influenced by other factors, such as patient selection, tic severity before surgery, age, sex, poor compliance, medication, placebo effect in openlabel settings, or stimulation parameters. Moreover, the wide time range of the maximum follow-up is another limitation, that may influence the results systematically. Taking into account the increase in the effectiveness of DBS over time, it may be considered problematic to report aggregated follow-up scores that span more than 6 months. For global YGTSS scores, we were unable to further narrow down the time category T3 (>12 months), because of insufficient data. Therefore, no statistical analyses were reasonably possible to examine whether the beneficial effects ceased over time. For the future, the use of international registries might contribute as part of the solution for this problem (146). It would also have been worthwhile to examine whether the increase of clinical efficacy of DBS differs between the four targets. Unfortunately, this was also not possible due to insufficient data. Another limitation refers to the assessment of TS symptomatology. The diversity of symptoms is not reflected in mean scores, such as the global YGTSS or YBOCS score. Thus, the heterogeneity of tics and comorbid symptoms was not considered in the present analysis. Moreover, to evaluate the effect of DBS on more of the heterogenous symptoms of TS, it would have been helpful to include additional psychiatric scales in the final analysis, including assessments of the premonitory urge (Premonitory Urge for Tic Scale-PUTS), and quality of life (Gilles de la Tourette Syndrome-Quality of Life Scale-GTS-QoL) $(147,148)$. However, these assessments were very rarely used in the included studies. Lastly, no side effects of DBS were reviewed in the present work. These limitations should be considered when planning and conducting future research, especially randomized controlled and double-blinded trials.

\section{CONCLUSION}

We conclude that DBS is a clinically effective treatment option for patients with treatment-refractory TS, with all targets showing comparable significant improvement rates. However, the present results suggest that reduction rates in tic symptoms may differ across targets up to 12 months after surgery. Importantly, it may take at least 1 year for the positive effects of DBS to fully develop, and therefore no conclusions can be drawn about potential differences in long-term clinical outcomes between targets. Future research might shift its focus away from identifying one appropriate target for DBS in TS and instead enable personalized and symptom-specific target selection. A first step in this direction might be the characterization of target- and symptom-specific networks modulated by DBS.

\section{DATA AVAILABILITY STATEMENT}

The original contributions presented in the study are included in the article/Supplementary Materials, further inquiries can be directed to the corresponding author.

\section{AUTHOR CONTRIBUTIONS}

The study has been designed by LW, TS, VV-V, JB, and PA. The literature search was conducted and data have been extracted by LW and JK. Data have been analyzed and interpreted by LW, TS, JB, and PA. The manuscript has been drafted by LW. Figures have been created by LW and PH. All authors revised and edited the manuscript.

\section{FUNDING}

This study was supported by the German Research Foundation (SFB 1451, Project ID 431549029-C07) and the Marga und Walter Boll Stiftung (210-06-16).

\section{SUPPLEMENTARY MATERIAL}

The Supplementary Material for this article can be found online at: https://www.frontiersin.org/articles/10.3389/fneur. 2021.769275/full\#supplementary-material

Supplementary Figure 1 | Summary table of risk of bias domains in each RCT created with the risk of bias visualization (robvis) tool (149).

Supplementary Material 1 | Search terms. 


\section{REFERENCES}

1. Efron D, Dale RC. Tics and Tourette syndrome. J Paediatr Child Health. (2018) 54:1148-53. doi: 10.1111/jpc.14165

2. Leckman JF, Zhang H, Vitale A, Lahnin F, Lynch K, Bondi C, et al. Course of tic severity in Tourette syndrome: the first two decades. Pediatrics. (1998) 102:14-9. doi: 10.1542/peds.102.1.14

3. Eapen V, Cavanna AE, Robertson MM. Comorbidities, social impact, and quality of life in Tourette syndrome. Front Psychiatry. (2016) 7:97. doi: 10.3389/fpsyt.2016.00097

4. Zinner SH, Conelea CA, Glew GM, Woods DW, Budman CL. Peer victimization in youth with Tourette syndrome and other chronic tic disorders. Child Psychiatry Hum Dev. (2012) 43:124-36. doi: 10.1007/s10578-011-0249-y

5. Ganos C, Roessner V, Münchau A. The functional anatomy of Gilles de la Tourette syndrome. Neurosci Biobehav Rev. (2013) 37:1050-62. doi: 10.1016/j.neubiorev.2012.11.004

6. Albin RL, Mink JW. Recent advances in Tourette syndrome research. Trends Neurosci. (2006) 29:175-82. doi: 10.1016/j.tins.2006.01.001

7. Mink JW. The basal ganglia and involuntary movements: impaired inhibition of competing motor patterns. Arch Neurol. (2003) 60:1365-8. doi: 10.1001/archneur.60.10.1365

8. Leckman JF, Vaccarino FM, Kalanithi PSA, Rothenberger A. Annotation: Tourette syndrome: a relentless drumbeat - driven by misguided brain oscillations. J Child Psychol Psychiatry. (2006) 47:537-50. doi: 10.1111/j.1469-7610.2006.01620.x

9. Rae CL, Critchley HD, Seth AK. A bayesian account of the sensory-motor interactions underlying symptoms of Tourette syndrome. Front Psychiatry. (2019) 10:29. doi: 10.3389/fpsyt.2019.00029

10. Wang Z, Maia TV, Marsh R, Colibazzi T, Gerber A, Peterson BS. The neural circuits that generate tics in Tourette's syndrome. Am J Psychiatry. (2011) 168:1326-37. doi: 10.1176/appi.ajp.2011.09111692

11. Worbe Y, Malherbe C, Hartmann A, Pélégrini-Issac M, Messé A, Vidailhet M, et al. Functional immaturity of cortico-basal ganglia networks in Gilles de la Tourette syndrome. Brain. (2012) 135:1937-46. doi: 10.1093/brain/aws056

12. Polyanska L, Critchley HD, Rae CL. Centrality of prefrontal and motor preparation cortices to Tourette syndrome revealed by meta-analysis of task-based neuroimaging studies. NeuroImage Clin. (2017) 16:257-67. doi: 10.1016/j.nicl.2017.08.004

13. Robertson MM. Diagnosing Tourette syndrome: is it a common disorder? J Psychosom Res. (2003) 55:3-6. doi: 10.1016/S0022-3999(02)00580-9

14. Leckman JF, Cohen DJ. Tourette's Syndrome-tics, Obsessions, Compulsions: Developmental Psychopathology and Clinical Care. Hoboken, NJ: John Wiley \& Sons Inc (1999).

15. Gill CE, Kompoliti K. Clinical features of Tourette syndrome. J Child Neurol. (2020) 35:166-74. doi: 10.1177/0883073819877335

16. Azrin NH, Nunn RG. Habit-reversal: a method of eliminating nervous habits and tics. Behav Res Ther. (1973) 11:619-28. doi: 10.1016/0005-7967(73)90119-8

17. Frank M, Cavanna AE. Behavioural treatments for Tourette syndrome: an evidence-based review. Behav Neurol. (2013) 27:105-17. doi: $10.1155 / 2013 / 134863$

18. Wilhelm S, Peterson AL, Piacentini J, Woods DW, Deckersbach T, Sukhodolsky DG, et al. Randomized trial of behavior therapy for adults with Tourette syndrome. Arch Gen Psychiatry. (2012) 69:795-803. doi: 10.1001/archgenpsychiatry.2011.1528

19. Huys D, Hardenacke K, Poppe P, Bartsch C, Baskin B, Kuhn J. Update on the Role of Antipsychotics in the Treatment of Tourette Syndrome. Neuropsychiatr Dis Treat. (2012) 8:95-104. doi: 10.2147/NDT.S12990

20. Johnson MD, Miocinovic S, McIntyre CC, Vitek JL. Mechanisms and targets of deep brain stimulation in movement disorders. Neurotherapeutics. (2008) 5:294-308. doi: 10.1016/j.nurt.2008.01.010

21. Vandewalle V, van der Linden C, Groenewegen HJ, Caemaert J. Stereotactic treatment of Gilles de la Tourette syndrome by high frequency stimulation of thalamus. Lancet. (1999) 353:724. doi: 10.1016/S0140-6736(98)05964-9

22. Hassler R, Dieckmann G. Stereotaxic treatment of tics and inarticulate cries or coprolalia considered as motor obsessional phenomena in Gilles de la Tourette's disease. Rev Neurol. (1970) 123:89-100.
23. Ilyas A, Pizarro D, Romeo AK, Riley KO, Pati S. The centromedian nucleus: anatomy, physiology, and clinical implications. J Clin Neurosci. (2019) 63:1-7. doi: 10.1016/j.jocn.2019.01.050

24. Sadikot AF, Rymar VV. The primate centromedian-parafascicular complex: anatomical organization with a note on neuromodulation. Brain Res Bull. (2009) 78:122-30. doi: 10.1016/j.brainresbull.2008.09.016

25. Van der Werf YD, Witter MP, Groenewegen HJ. The intralaminar and midline nuclei of the thalamus. Anatomical and functional evidence for participation in processes of arousal and awareness. Brain Res Rev. (2002) 39:107-40. doi: 10.1016/S0165-0173(02)00181-9

26. Cacciola A, Milardi D, Bertino S, Basile GA, Calamuneri A, Chillemi G, et al. Structural connectivity-based topography of the human globus pallidus: implications for therapeutic targeting in movement disorders. Mov Disord. (2019) 34:987-96. doi: $10.1002 / \mathrm{mds} .27712$

27. Nambu A. Somatotopic organization of the primate basal ganglia. Front Neuroanat. (2011) 5:26. doi: 10.3389/fnana.2011.00026

28. Worbe Y, Marrakchi-Kacem L, Lecomte S, Valabregue R, Poupon F, Guevara $\mathrm{P}$, et al. Altered structural connectivity of cortico-striato-pallido-thalamic networks in Gilles de la Tourette syndrome. Brain. (2014) 138:472-82. doi: 10.1093/brain/awu311

29. Nair G, Evans A, Bear RE, Velakoulis D, Bittar RG. The anteromedial GPi as a new target for deep brain stimulation in obsessive compulsive disorder. J Clin Neurosci. (2014) 21:815-21. doi: 10.1016/j.jocn.2013. 10.003

30. Servello D, Galbiati TF, Balestrino R, Iess G, Zekaj E, Michele S, et al. Deep brain stimulation for Gilles de la Tourette syndrome: toward limbic targets. Brain Sci. (2020) 10:301. doi: 10.3390/brainsci10050301

31. Johnson KA, Duffley G, Anderson DN, Ostrem JL, Welter ML, Baldermann JC, et al. Structural connectivity predicts clinical outcomes of deep brain stimulation for Tourette syndrome. Brain. (2020) 143:2607-23. doi: 10.1093/brain/awaa188

32. Heiden P, Hoevels M, Bayram D, Baldermann JC, Schuller T, Huys $\mathrm{D}$, et al. Connectivity patterns of deep brain stimulation targets in patients with Gilles de la Tourette syndrome. Brain Sci. (2021) 11:87. doi: 10.3390/brainsci11010087

33. Ackermans L, Temel Y, Cath D, van der Linden C, Bruggeman R, Kleijer $\mathrm{M}$, et al. Deep brain stimulation in Tourette's syndrome: two targets? Mov Disord. (2006) 21:709-13. doi: 10.1002/mds.20816

34. Porta M, Saleh C, Zekaj E, Zanaboni Dina C, Bona AR, Servello D. Why so many deep brain stimulation targets in Tourette's syndrome? Toward a broadening of the definition of the syndrome. J Neural Transm. (2016) 123:785-90. doi: 10.1007/s00702-015-1494-1

35. Viswanathan A, Jimenez-Shahed J, Baizabal Carvallo JF, Jankovic J. Deep brain stimulation for Tourette syndrome: target selection. Stereotact Funct Neurosurg. (2012) 90:213-24. doi: 10.1159/000337776

36. Baldermann JC, Schüller T, Huys D, Becker I, Timmermann L, Jessen F, et al. Deep brain stimulation for Tourette-syndrome: a systematic review and meta-analysis. Brain Stimul. (2016) 9:296-304. doi: 10.1016/j.brs.2015.11.005

37. Martinez-Ramirez D, Jimenez-Shahed J, Leckman JF, Porta M, Servello D, Meng FG, et al. Efficacy and safety of deep brain stimulation in Tourette syndrome: the international Tourette syndrome deep brain stimulation public database and registry. JAMA Neurol. (2018) 75:353-9. doi: 10.1001/jamaneurol.2017.4317

38. Xu W, Zhang C, Deeb W, Patel B, Wu Y, Voon V, et al. Deep brain stimulation for Tourette's syndrome. Transl Neurodegener. (2020) 9:4. doi: 10.1186/s40035-020-0183-7

39. Horn A. The impact of modern-day neuroimaging on the field of deep brain stimulation. Curr Opin Neurol. (2019) 32:511-20. doi: 10.1097/WCO.0000000000000679

40. Ashkan K, Rogers P, Bergman H, Ughratdar I. Insights into the mechanisms of deep brain stimulation. Nat Rev Neurol. (2017) 13:548-54. doi: 10.1038/nrneurol.2017.105

41. McIntyre CC, Hahn PJ. Network perspectives on the mechanisms of deep brain stimulation. Neurobiol Dis. (2010) 38:329-37. doi: 10.1016/j.nbd.2009.09.022

42. Deeb W, Malaty I. Deep brain stimulation for Tourette syndrome: potential role in the pediatric population. J Child Neurol. (2020) 35:155-65. doi: $10.1177 / 0883073819872620$ 
43. Porta M, Servello D, Sassi M, Brambilla A, Defendi S, Priori A, et al. Issues related to deep brain stimulation for treatment-refractory Tourette's syndrome. Eur Neurol. (2009) 62:264-73. doi: 10.1159/000235595

44. Page MJ, McKenzie JE, Bossuyt PM, Boutron I, Hoffmann TC, Mulrow CD, et al. The PRISMA 2020 statement: an updated guideline for reporting systematic reviews. BMJ. (2021) 372:n71. doi: 10.1136/bmj.n71

45. French J, Gronseth G. Invited article: lost in a jungle of evidence: we need a compass. Neurology. (2008) 71:1634-8. doi: 10.1212/01.wnl.0000336533.19610.1b

46. Higgins JP, Thomas J, Chandler J, Cumpston M, Li T, Page MJ, et al. Cochrane Handbook for Systematic Reviews of Interventions: Chichester, UK: John Wiley \& Sons (2019). doi: 10.1002/9781119536604

47. IBM Corp. IBM SPSS Statistics for Windows, Version 27.0. Armonk, NY: IBM Corp (202).

48. The Cochrane Collaboration. Review Manager (RevMan) [Computer program]. Version 5.4. The Cochrane Collaboration (2020).

49. Diederich NJ, Kalteis K, Stamenkovic M, Pieri V, Alesch F. Efficient internal pallidal stimulation in Gilles de la Tourette syndrome: a case report. Mov Disord. (2005) 20:1496-9. doi: 10.1002/mds.20551

50. Bajwa RJ, de Lotbiniere AJ, King RA, Jabbari B, Quatrano S, Kunze K, et al. Deep brain stimulation in Tourette's syndrome. Mov Disord. (2007) 22:1346-50. doi: 10.1002/mds. 21398

51. Kuhn J, Lenartz D, Mai JK, Huff W, Lee SH, Koulousakis A, et al. Deep brain stimulation of the nucleus accumbens and the internal capsule in therapeutically refractory Tourette-syndrome. J Neurol. (2007) 254:963-5. doi: 10.1007/s00415-006-0404-8

52. Maciunas RJ, Maddux BN, Riley DE, Whitney CM, Schoenberg MR, Ogrocki PJ, et al. Prospective randomized double-blind trial of bilateral thalamic deep brain stimulation in adults with Tourette syndrome. J Neurosurg. (2007) 107:1004-14. doi: 10.3171/JNS-07/11/1004

53. Shahed J, Poysky J, Kenney C, Simpson R, Jankovic J. GPi deep brain stimulation for Tourette syndrome improves tics and psychiatric comorbidities. Neurology. (2007) 68:159-60. doi: 10.1212/01.wnl.0000250354.81556.90

54. Shields DC, Cheng ML, Flaherty AW, Gale JT, Eskandar EN. Microelectrodeguided deep brain stimulation for Tourette syndrome: within-subject comparison of different stimulation sites. Stereotact Funct Neurosurg. (2008) 86:87-91. doi: 10.1159/000112429

55. Dehning S, Mehrkens JH, Müller N, Bötzel K. Therapy-refractory Tourette syndrome: beneficial outcome with globus pallidus internus deep brain stimulation. Mov Disord. (2008) 23:1300-2. doi: 10.1002/mds.21930

56. Kuhn J, Lenartz D, Huff W, Mai JK, Koulousakis A, Maarouf M, et al. Transient manic-like episode following bilateral deep brain stimulation of the nucleus accumbens and the internal capsule in a patient with Tourette syndrome. Neuromodulation. (2008) 11:128-31. doi: 10.1111/j.1525-1403.2008.00154.x

57. Neuner I, Podoll K, Lenartz D, Sturm V, Schneider F. Deep brain stimulation in the nucleus accumbens for intractable Tourette's syndrome: follow-up report of 36 months. Biol Psychiatry. (2009) 65:e5-6. doi: 10.1016/j.biopsych.2008.09.030

58. Servello D, Sassi M, Brambilla A, Defendi S, Porta M. Long-term, postdeep brain stimulation management of a series of 36 patients affected with refractory Gilles de la Tourette syndrome. Neuromodulation. (2010) 13:187-94. doi: 10.1111/j.1525-1403.2009.00253.x

59. Servello D, Sassi M, Brambilla A, Porta M, Haq I, Foote KD, et al. De novo and rescue DBS leads for refractory Tourette syndrome patients with severe comorbid OCD: a multiple case report. J Neurol. (2009) 256:1533-9. doi: 10.1007/s00415-009-5159-6

60. Burdick A, Foote KD, Goodman W, Ward HE, Ricciuti N, Murphy T, et al. Lack of benefit of accumbens/capsular deep brain stimulation in a patient with both tics and obsessive-compulsive disorder. Neurocase. (2010) 16:321-30. doi: 10.1080/13554790903560422

61. Marceglia S, Servello D, Foffani G, Porta M, Sassi M, Mrakic-Sposta S, et al. Thalamic single-unit and local field potential activity in Tourette syndrome. Mov Disord. (2010) 25:300-8. doi: 10.1002/mds.22982

62. Ackermans L, Duits A, van der Linden C, Tijssen M, Schruers K, Temel $\mathrm{Y}$, et al. Double-blind clinical trial of thalamic stimulation in patients with Tourette syndrome. Brain. (2011) 134:832-44. doi: 10.1093/brain/awq380
63. Pullen SJ, Wall CA, Lee KH, Stead SM, Klassen BT, Brown TM. Neuropsychiatric outcome of an adolescent who received deep brain stimulation for Tourette's syndrome. Case Rep Neurol Med. (2011) 2011:209467. doi: 10.1155/2011/209467

64. Kaido T, Otsuki T, Kaneko Y, Takahashi A, Omori M, Okamoto T. Deep brain stimulation for Tourette syndrome: a prospective pilot study in Japan. Neuromodulation. (2011) 14:123-8. doi: 10.1111/j.1525-1403.2010.00324.x

65. Kuhn J, Bartsch C, Lenartz D, Huys D, Daumann J, Woopen C, et al. Clinical effectiveness of unilateral deep brain stimulation in Tourette syndrome. Transl Psychiatry. (2011) 1:e52. doi: 10.1038/tp.2011.51

66. Lee MW, Au-Yeung MM, Hung KN, Wong CK. Deep brain stimulation in a Chinese Tourette's syndrome patient. Hong Kong Med J. (2011) 17:147-50.

67. Martínez-Fernández R, Zrinzo L, Aviles-Olmos I, Hariz M, Martinez-Torres I, Joyce E, et al. Deep brain stimulation for Gilles de la Tourette syndrome: a case series targeting subregions of the globus pallidus internus. Mov Disord. (2011) 26:1922-30. doi: 10.1002/mds.23734

68. Rzesnitzek L, Wachter T, Kruger R, Gharabaghi A, Plewnia C. Suppression of extrapyramidal side effects of doxepin by thalamic deep brain stimulation for Tourette syndrome. Neurology. (2011) 77:1708-9. doi: 10.1212/WNL.0b013e318236485f

69. Savica R, Stead M, Mack KJ, Lee KH, Klassen BT. Deep brain stimulation in Tourette syndrome: a description of 3 patients with excellent outcome. Mayo Clin Proc. (2012) 87:59-62. doi: 10.1016/j.mayocp.2011.08.005

70. Dong S, Zhuang P, Zhang XH, Li JY, Li YJ. Unilateral deep brain stimulation of the right globus pallidus internus in patients with Tourette's syndrome: two cases with outcomes after 1 year and a brief review of the literature. J Int Med Res. (2012) 40:2021-8. doi: 10.1177/030006051204000545

71. Duits A, Ackermans L, Cath D, Visser-Vandewalle V. Unfavourable outcome of deep brain stimulation in a Tourette patient with severe comorbidity. Eur Child Adolesc Psychiatry. (2012) 21:529-31. doi: 10.1007/s00787-012-0285-6

72. Sachdev PS, Cannon E, Coyne TJ, Silburn P. Bilateral deep brain stimulation of the nucleus accumbens for comorbid obsessive compulsive disorder and Tourette's syndrome. BMJ Case Rep. (2012) 2012. doi: 10.1136/bcr-2012-006579

73. Massano J, Sousa C, Foltynie T, Zrinzo L, Hariz M, Vaz R. Successful pallidal deep brain stimulation in 15-year-old with Tourette syndrome: 2-year follow-up. J Neurol. (2013) 260:2417-9. doi: 10.1007/s00415-013-7049-1

74. Motlagh MG, Smith ME, Landeros-Weisenberger A, Kobets AJ, King RA, Miravite J, et al. Lessons learned from open-label deep brain stimulation for Tourette syndrome: eight cases over 7 years. Tremor Other Hyperkinet Mov. (2013) 3:tre-03-170-4428-1. doi: 10.5334/tohm.126

75. Okun MS, Foote KD, Wu SS, Ward HE, Bowers D, Rodriguez RL, et al. A trial of scheduled deep brain stimulation for Tourette syndrome: moving away from continuous deep brain stimulation paradigms. JAMA Neurol. (2013) 70:85-94. doi: 10.1001/jamaneurol.2013.580

76. Piedimonte F, Andreani JC, Piedimonte L, Graff P, Bacaro V, Micheli F, et al. Behavioral and motor improvement after deep brain stimulation of the globus pallidus externus in a case of Tourette's syndrome. Neuromodulation. (2013) 16:55-8. doi: 10.1111/j.1525-1403.2012.00526.x

77. Dehning S, Leitner B, Schennach R, Muller N, Botzel K, Obermeier M, et al. Functional outcome and quality of life in Tourette's syndrome after deep brain stimulation of the posteroventrolateral globus pallidus internus: long-term follow-up. World J Biol Psychiatry. (2014) 15:66-75. doi: 10.3109/15622975.2013.849004

78. Dong S, Zhang X, Li J, Li Y. The benefits of low-frequency pallidal deep brain stimulation in a patient with Tourette syndrome. Parkinsonism Relat Disord. (2014) 20:1438-9. doi: 10.1016/j.parkreldis.2014.09.028

79. Huasen B, McCreary R, Evans J, Potter G, Silverdale M. Cervical myelopathy secondary to Tourette's syndrome managed by urgent deep brain stimulation. Mov Disord. (2014) 29:452-3. doi: 10.1002/mds.25797

80. Patel N, Jimenez-Shahed J. Simultaneous improvement of tics and parkinsonism after pallidal DBS. Parkinsonism Relat Disord. (2014) 20:10223. doi: 10.1016/j.parkreldis.2014.05.009

81. Pourfar MH, Budman CL, Mogilner AY. A case of deep brain stimulation for Tourette's complicated by twiddler's syndrome. Mov Disord Clin Pract. (2015) 2:192-3. doi: 10.1002/mdc3.12132

82. Sachdev PS, Mohan A, Cannon E, Crawford JD, Silberstein P, Cook R, et al. Deep brain stimulation of the antero-medial globus 
pallidus interna for Tourette syndrome. PLoS ONE. (2014) 9:e104926. doi: 10.1371/journal.pone. 0104926

83. Cannon E, Silburn P, Coyne T, O’Maley K, Crawford JD, Sachdev PS. Deep brain stimulation of anteromedial globus pallidus interna for severe Tourette's syndrome. Am J Psychiatry. (2012) 169:860-6. doi: 10.1176/appi.ajp.2012.11101583

84. Zhang JG, Ge Y, Stead M, Zhang K, Yan SS, Hu W, et al. Longterm outcome of globus pallidus internus deep brain stimulation in patients with Tourette syndrome. Mayo Clin Proc. (2014) 89:1506-14. doi: 10.1016/j.mayocp.2014.05.019

85. Kefalopoulou Z, Zrinzo L, Jahanshahi M, Candelario J, Milabo C, Beigi M, et al. Bilateral globus pallidus stimulation for severe Tourette's syndrome: a double-blind, randomised crossover trial. Lancet Neurol. (2015) 14:595-605. doi: $10.1016 /$ S1474-4422(15)00008-3

86. Morreale F, Kefalopoulou Z, Zrinzo L, Limousin P, Joyce E, Foltynie T, et al. Inhibitory control on a stop signal task in Tourette syndrome before and after deep brain stimulation of the internal segment of the globus pallidus. Brain Sci. (2021) 11:461. doi: 10.3390/brainsci11040461

87. Wardell K, Kefalopoulou Z, Diczfalusy E, Andersson M, Astrom M, Limousin P, et al. Deep brain stimulation of the pallidum internum for Gilles de la Tourette syndrome: a patient-specific model-based simulation study of the electric field. Neuromodulation. (2015) 18:90-6. doi: 10.1111/ner. 12248

88. Cury RG, Lopez WO, Dos Santos Ghilardi MG, Barbosa DC, Barbosa ER, Teixeira MJ, et al. Parallel improvement in anxiety and tics after DBS for medically intractable Tourette syndrome: a long-term follow-up. Clin Neurol Neurosurg. (2016) 144:33-5. doi: 10.1016/j.clineuro.2016.02.030

89. Huys D, Bartsch C, Koester P, Lenartz D, Maarouf M, Daumann J, et al. Motor improvement and emotional stabilization in patients with Tourette syndrome after deep brain stimulation of the ventral anterior and ventrolateral motor part of the thalamus. Biol Psychiatry. (2016) 79:392-401. doi: 10.1016/j.biopsych.2014.05.014

90. Smeets A, Duits AA, Plantinga BR, Leentjens AFG, Oosterloo M, VisserVandewalle V, et al. Deep brain stimulation of the internal globus pallidus in refractory Tourette syndrome. Clin Neurol Neurosurg. (2016) 142:54-9. doi: 10.1016/j.clineuro.2016.01.020

91. Testini P, Zhao CZ, Stead M, Duffy PS, Klassen BT, Lee KH. Centromedian-Parafascicular complex deep brain stimulation for Tourette syndrome: a retrospective study. Mayo Clin Proc. (2016) 91:218-25. doi: 10.1016/j.mayocp.2015.11.016

92. Zhang XH, Li JY, Zhang YQ, Li YJ. Deep brain stimulation of the globus pallidus internus in patients with intractable Tourette syndrome: a 1-year follow-up study. Chin Med J. (2016) 129:1022-7. doi: 10.4103/0366-6999.180512

93. Akbarian-Tefaghi L, Akram H, Johansson J, Zrinzo L, Kefalopoulou Z, Limousin P, et al. Refining the deep brain stimulation target within the limbic globus pallidus internus for Tourette syndrome. Stereotact Funct Neurosurg. (2017) 95:251-8. doi: 10.1159/000478273

94. Dwarakanath S, Hegde A, Ketan J, Chandrajit P, Yadav R, Keshav K, et al. "I swear, I can't stop it!" - a case of severe Tourette's syndrome treated with deep brain stimulation of anteromedial globus pallidus interna. Neurol India. (2017) 65:99-102. doi: 10.4103/0028-3886.198188

95. Neudorfer C, El Majdoub F, Hunsche S, Richter K, Sturm V, Maarouf M. Deep Brain stimulation of the $\mathrm{H}$ fields of forel alleviates tics in Tourette syndrome. Front Hum Neurosci. (2017) 11:308. doi: $10.3389 /$ fnhum.2017.00308

96. Picillo M, Rohani M, Lozano AM, Fasano A. Two indications, one target: concomitant epilepsy and tourettism treated with centromedian/parafascicular thalamic stimulation. Brain Stimul. (2017) 10:711-3. doi: 10.1016/j.brs.2017.01.577

97. Welter M-L, Houeto J-L, Thobois S, Bataille B, Guenot M, Worbe Y, et al. Anterior pallidal deep brain stimulation for Tourette's syndrome: a randomised, double-blind, controlled trial. Lancet Neurol. (2017) 16:610-9. doi: 10.1016/S1474-4422(17)30160-6

98. Azimi A, Parvaresh M, Shahidi G, Habibi A, Rohani S, Safdarian M, et al. Anteromedial GPi deep brain stimulation in Tourette syndrome: the first case series from Iran. Clin Neurol Neurosurg. (2018) 172:116-9. doi: 10.1016/j.clineuro.2018.06.045
99. Doshi PK, Ramdasi R, Thorve S. Deep brain stimulation of anteromedial globus pallidus internus for severe Tourette syndrome. Indian J Psychiatry. (2018) 60:138-40. doi: 10.4103/psychiatry.IndianJPsychiatry_53_18

100. Dowd RS, Pourfar M, Mogilner AY. Deep brain stimulation for Tourette syndrome: a single-center series. J Neurosurg. (2018) 128:596-604. doi: 10.3171/2016.10.JNS161573

101. Kano Y, Matsuda N, Nonaka M, Fujio M, Kono T, Kaido T. Sensory phenomena and obsessive-compulsive symptoms in Tourette syndrome following deep brain stimulation: two case reports. J Clin Neurosci. (2018) 56:199-201. doi: 10.1016/j.jocn.2018.06.046

102. Richieri R, Blackman G, Musil R, Spatola G, Cavanna AE, Lancon $\mathrm{C}$, et al. Positive clinical effects of gamma knife capsulotomy in a patient with deep brain stimulation-refractory Tourette syndrome and obsessive compulsive disorder. Clin Neurol Neurosurg. (2018) 170:34-7. doi: 10.1016/j.clineuro.2018.04.018

103. Brito M, Teixeira MJ, Mendes MM, Franca C, Iglesio R, Barbosa ER, et al. Exploring the clinical outcomes after deep brain stimulation in Tourette syndrome. J Neurol Sci. (2019) 402:48-51. doi: 10.1016/j.jns.2019.05.011

104. Kakusa B, Saluja S, Tate WJ, Espil FM, Halpern CH, Williams NR. Robust clinical benefit of multi-target deep brain stimulation for treatment of Gilles de la Tourette syndrome and its comorbidities. Brain Stimul. (2019) 12:816-8. doi: 10.1016/j.brs.2019.02.026

105. Rossi M, Cerquetti D, Cammarota A, Merello M. Tourette syndrome: clinical benefit with unilateral stimulation after bilateral pallidal implant. Mov Disord. (2019) 34:580-2. doi: 10.1002/mds.27636

106. Zhang C, Li H, Pan Y, Jin H, Sun B, Wu Y, et al. Pallidal neurostimulation and capsulotomy for malignant Tourette's syndrome. Mov Disord Clin Pract. (2019) 6:393-5. doi: 10.1002/mdc3.12761

107. Zhang C, Deng Z, Pan Y, Zhang J, Zeljic K, Jin H, et al. Pallidal deep brain stimulation combined with capsulotomy for Tourette's syndrome with psychiatric comorbidity. J Neurosurg. (2019) 131:1788-96. doi: $10.3171 / 2018.8$.JNS181339

108. Zhu GY, Geng XY, Zhang RL, Chen YC, Liu YY, Wang SY, et al. Deep brain stimulation modulates pallidal and subthalamic neural oscillations in Tourette's syndrome. Brain Behav. (2019) 9:e01450. doi: 10.1002/brb3.1450

109. Duarte-Batista P, Coelho M, Quintas S, Levy P, Castro Caldas A, GoncalvesFerreira A, et al. Anterior limb of internal capsule and bed nucleus of stria terminalis stimulation for Gilles de la Tourette syndrome with obsessivecompulsive disorder in adolescence: a case of success. Stereotact Funct Neurosurg. (2020) 98:95-103. doi: 10.1159/000505702

110. Servello D, Zekaj E, Saleh C, Lange N, Porta M. Deep brain stimulation in Gilles de la Tourette syndrome: what does the future hold? A cohort of 48 patients. Neurosurgery. (2016) 78:91-100. doi: 10.1227/NEU.0000000000001004

111. Servello D, Porta M, Sassi M, Brambilla A, Robertson MM. Deep brain stimulation in 18 patients with severe Gilles de la Tourette syndrome refractory to treatment: the surgery and stimulation. J Neurol Neurosurg Psychiatry. (2008) 79:136-42. doi: 10.1136/jnnp.2006.104067

112. Porta M, Brambilla A, Cavanna AE, Servello D, Sassi M, Rickards $\mathrm{H}$, et al. Thalamic deep brain stimulation for treatment-refractory Tourette syndrome: two-year outcome. Neurology. (2009) 73:1375-80. doi: 10.1212/WNL.0b013e3181bd809b

113. Porta M, Servello D, Zanaboni C, Anasetti F, Menghetti C, Sassi $\mathrm{M}$, et al. Deep brain stimulation for treatment of refractory Tourette syndrome: long-term follow-up. Acta Neurochir. (2012) 154:2029-41. doi: 10.1007/s00701-012-1497-8

114. Marceglia S, Prenassi M, Galbiati TF, Porta M, Zekaj E, Priori A, et al. Thalamic local field potentials are related to long-term DBS effects in Tourette syndrome. Front Neurol. (2021) 12:578324. doi: 10.3389/fneur.2021.578324

115. Andrade P, Heiden P, Hoevels M, Schlamann M, Baldermann JC, Huys $\mathrm{D}$, et al. Modulation of fibers to motor cortex during thalamic DBS in Tourette patients correlates with tic reduction. Brain Sci. (2020) 10(5). doi: 10.3390/brainsci10050302

116. Kimura Y, Iijima K, Takayama Y, Yokosako S, Kaneko Y, Omori $M$, et al. Deep brain stimulation for refractory Tourette syndrome: electrode position and clinical outcome. Neurol Med Chir. (2021) 61:33-9. doi: 10.2176/nmc.oa.2020-0202 
117. Müller-Vahl KR, Szejko N, Saryyeva A, Schrader C, Krueger D, Horn A, et al. Randomized double-blind sham-controlled trial of thalamic versus GPi stimulation in patients with severe medically refractory Gilles de la Tourette syndrome. Brain Stimul. (2021) 14:662-75. doi: 10.1016/j.brs.2021.04.004

118. Sun F, Zhang X, Dong S, Zhang Y, Li J, Wang Y, et al. Effectiveness of lowfrequency pallidal deep brain stimulation at $65 \mathrm{hz}$ in Tourette syndrome. Neuromodulation. (2021). doi: 10.1111/ner.13456 [Epub ahead of print].

119. Baldermann JC, Kuhn J, Schüller T, Kohl S, Andrade P, Schleyken S, et al. Thalamic deep brain stimulation for Tourette syndrome: a naturalistic trial with brief randomized, double-blinded sham-controlled periods. Brain Stimul. (2021) 14:1055-418. doi: 10.1016/j.brs.2021.07.003

120. Ewert S, Plettig P, Li N, Chakravarty MM, Collins DL, Herrington TM, et al. Toward defining deep brain stimulation targets in MNI space: a subcortical atlas based on multimodal MRI, histology and structural connectivity. Neuroimage. (2018) 170:271-82. doi: 10.1016/j.neuroimage.2017.05.015

121. Xiao Y, Fonov V, Chakravarty MM, Beriault S, Al Subaie F, Sadikot A, et al. A dataset of multi-contrast population-averaged brain MRI atlases of a Parkinson's disease cohort. Data Brief. (2017) 12:370-9. doi: 10.1016/j.dib.2017.04.013

122. Fayad SM, Guzick AG, Reid AM, Mason DM, Bertone A, Foote KD, et al. Six-nine year follow-up of deep brain stimulation for obsessive-compulsive disorder. PLoS ONE. (2016) 11:e0167875. doi: 10.1371/journal.pone.0167875

123. Mahajan UV, Purger DA, Mantovani A, Williams NR, Espil FM, Han SS, et al. Deep brain stimulation results in greater symptomatic improvement in Tourette syndrome than conservative measures: a meta-analysis. Stereotact Funct Neurosurg. (2020) 98:270-7. doi: 10.1159/000507059

124. Hirschtritt ME, Lee PC, Pauls DL, Dion Y, Grados MA, Illmann C, et al. Lifetime prevalence, age of risk, and genetic relationships of comorbid psychiatric disorders in Tourette syndrome. JAMA Psychiatry. (2015) 72:325-33. doi: 10.1001/jamapsychiatry.2014.2650

125. Macchi G, Jones EG. Toward an agreement on terminology of nuclear and subnuclear divisions of the motor thalamus. J Neurosurg. (1997) 86:670-85. doi: 10.3171/jns.1997.86.4.0670

126. Mai JK, Majtanik M. Toward a common terminology for the thalamus. Front Neuroanat. (2019) 12:114. doi: 10.3389/fnana.2018.00114

127. Visser-Vandewalle V, Temel Y, Boon P, Vreeling F, Colle H, Hoogland G, et al. Chronic bilateral thalamic stimulation: a new therapeutic approach in intractable Tourette syndrome: report of three cases. J Neurosurg. (2003) 99:1094-100. doi: 10.3171/jns.2003.99.6.1094

128. Williams NR, Taylor JJ, Lamb K, Hanlon CA, Short EB, George MS. Role of functional imaging in the development and refinement of invasive neuromodulation for psychiatric disorders. World J Radiol. (2014) 6:756-78. doi: 10.4329/wjr.v6.i10.756

129. Krauss JK, Yianni J, Loher TJ, Aziz TZ. Deep brain stimulation for dystonia. J Clin Neurophysiol. (2004) 21:18-30. doi: 10.1097/00004691-200401000-00004

130. Yianni J, Bain P, Giladi N, Auca M, Gregory R, Joint C, et al. Globus pallidus internus deep brain stimulation for dystonic conditions: a prospective audit. Mov Disord. (2003) 18:436-42. doi: 10.1002/mds.10380

131. Johnson KA, Duffley G, Foltynie T, Hariz M, Zrinzo L, Joyce EM, et al. Basal ganglia pathways associated with therapeutic pallidal deep brain stimulation for Tourette syndrome. Biol Psychiatry Cogn Neurosci Neuroimaging. (2020). doi: 10.1016/j.bpsc.2020.11.005 [Epub ahead of print].

132. Szejko N, Müller-Vahl KR. Challenges in the diagnosis and assessment in patients with Tourette syndrome and comorbid obsessivecompulsive disorder. Neuropsychiatr Dis Treat. (2021) 17:1253-66. doi: 10.2147/NDT.S251499

133. Cath DC, Spinhoven P, Hoogduin CAL, Landman AD, van Woerkom TCAM, van de Wetering BJM, et al. Repetitive behaviors in Tourette's syndrome and OCD with and without tics: what are the differences? Psychiatry Res. (2001) 101:171-85. doi: 10.1016/S0165-1781(01)00219-0

134. Ganos C, Kahl U, Brandt V, Schunke O, Baumer T, Thomalla $\mathrm{G}$, et al. The neural correlates of tic inhibition in Gilles de la Tourette syndrome. Neuropsychologia. (2014) 65:297-301. doi: 10.1016/j.neuropsychologia.2014.08.007

135. van der Salm SMA, van der Meer JN, Cath DC, Groot PFC, van der Werf YD, Brouwers E, et al. Distinctive tics suppression network in Gilles de la Tourette syndrome distinguished from suppression of natural urges using multimodal imaging. Neuroimage Clin. (2018) 20:783-92. doi: 10.1016/j.nicl.2018.09.014
136. Schrock LE, Mink JW, Woods DW, Porta M, Servello D, Visser-Vandewalle $\mathrm{V}$, et al. Tourette syndrome deep brain stimulation: a review and updated recommendations. Mov Disord. (2015) 30:448-71. doi: 10.1002/mds. 26094

137. Welter ML, Mallet L, Houeto JL, Karachi C, Czernecki V, Cornu $\mathrm{P}$, et al. Internal pallidal and thalamic stimulation in patients with Tourette syndrome. Arch Neurol. (2008) 65:952-7. doi: 10.1001/archneur. 65.7.952

138. Van der Linden C, Colle H, Vandewalle V, Alessi G, Rijckaert D, De Waele L. Successful treatment of tics with bilateral internal pallidum (GPi) stimulation in a 27 -year-old male patient with Gilles de la Tourette's syndrome (GTS). Mov Disord. (2002) 17:S341-S.

139. Ackermans L, Duits A, Temel Y, Winogrodzka A, Peeters F, Beuls EA, et al. Long-term outcome of thalamic deep brain stimulation in two patients with Tourette syndrome. J Neurol Neurosurg Psychiatry. (2010) 81:1068-72. doi: 10.1136/jnnp.2009.176859

140. Servello D, Saleh C, Bona AR, Zekaj E, Porta M. After 19 years of deep brain stimulation in Tourette's syndrome: from multiple targets to one single target? Surg Neurol Int. (2018) 9:219. doi: 10.4103/sni.sni_271_18

141. Middlebrooks EH, Tuna I, Grewal S, Almeida L, Heckman M, Lesser E, et al Segmentation of the globus pallidus internus using probabilistic diffusion tractography for deep brain stimulation targeting in Parkinson disease. Am J Neuroradiol. (2018) 39:1127-34. doi: 10.3174/ajnr.A5641

142. Horn A, Fox MD. Opportunities of connectomic neuromodulation. Neuroimage. (2020) 221:117180. doi: 10.1016/j.neuroimage.2020.117180

143. Paulo DL, Bick SK. Advanced imaging in psychiatric neurosurgery: toward personalized treatment. Neuromodulation. (2021). doi: 10.1111/ner.13392 [Epub ahead of print].

144. Kakusa B, Saluja S, Barbosa DAN, Cartmell S, Espil FM, Williams NR, et al. Evidence for the role of the dorsal ventral lateral posterior thalamic nucleus connectivity in deep brain stimulation for Gilles de la Tourette syndrome. J Psychiatr Res. (2021) 132:60-4. doi: 10.1016/j.jpsychires.2020.09.024

145. Johnson KA, Fletcher PT, Servello D, Bona A, Porta M, Ostrem JL, et al. Image-based analysis and long-term clinical outcomes of deep brain stimulation for Tourette syndrome: a multisite study. J Neurol Neurosurg Psychiatry. (2019) 90:1078-90. doi: 10.1136/jnnp-2019-320379

146. Deeb W, Rossi PJ, Porta M, Visser-Vandewalle V, Servello D, Silburn P, et al. The international deep brain stimulation registry and database for Gilles de la Tourette syndrome: how does it work? Front Neurosci. (2016) 10:170. doi: 10.3389/fnins.2016.00170

147. Baumung L, Müller-Vahl K, Dyke K, Jackson G, Jackson S, Golm D, et al. Developing the premonitory urges for tic disorders scale-revised (PUTS-R). J Neuropsychol. (2021) 15:129-42. doi: 10.1111/jnp.12216

148. Cavanna AE, Schrag A, Morley D, Orth M, Robertson MM, Joyce E, et al. The Gilles de la Tourette syndrome-quality of life scale (GTS-QOL): development and validation. J Neurol. (2008) 71:1410-6. doi: 10.1212/01.wnl.0000327890.02893.61

149. McGuinness LA, Higgins JPT. Risk-of-bias VISualization (robvis): an R package and shiny web app for visualizing risk-of-bias assessments. Res Synth Methods. (2020) 12:55-61. doi: 10.1002/jrsm.1411

Conflict of Interest: The authors declare that the research was conducted in the absence of any commercial or financial relationships that could be construed as a potential conflict of interest.

Publisher's Note: All claims expressed in this article are solely those of the authors and do not necessarily represent those of their affiliated organizations, or those of the publisher, the editors and the reviewers. Any product that may be evaluated in this article, or claim that may be made by its manufacturer, is not guaranteed or endorsed by the publisher.

Copyright (c) 2021 Wehmeyer, Schüller, Kiess, Heiden, Visser-Vandewalle, Baldermann and Andrade. This is an open-access article distributed under the terms of the Creative Commons Attribution License (CC BY). The use, distribution or reproduction in other forums is permitted, provided the original author(s) and the copyright owner(s) are credited and that the original publication in this journal is cited, in accordance with accepted academic practice. No use, distribution or reproduction is permitted which does not comply with these terms. 